\title{
Fácies e paleoambientes em uma sucessão estratigráfica da porção central do Complexo Deltaico do Rio Paraíba do Sul (RJ, Brasil)
}

\author{
Josiane Branco PLANTZ', Thiago Gonçalves CARELLI', Leonardo BORGHI'T, Marcelo de \\ Araújo CARVALHO² \& Renato Rodriguez Cabral RAMOS² \\ 1 Laboratório de Geologia Sedimentar, Instituto de Geociências, Universidade Federal do Rio de \\ Janeiro. Av. Athos da Silveira Ramos, 274, S/J1-011. CEP 21.941-916, Rio de Janeiro, RJ, Brasil \\ (josianeplantz@gmail.com, carelli@geologia.ufrj.br, lborghi@geologia.ufrj.br). \\ 2 Departamento de Geologia e Paleontologia, Museu Nacional da Universidade Federal do Rio \\ de Janeiro. Quinta da Boa Vista s/n, São Cristóvão, CEP 20.940-040, Rio de Janeiro, RJ, Brasil \\ (mcarvalho@mn.ufrj.br, rramos@mn.ufrj.br).
}

Resumo. O Complexo Deltaico do Rio Paraíba do Sul (CDRPS), localizado no litoral norte do
Estado do Rio de Janeiro, é uma importante planície costeira de idade quaternária que engloba
parte da porção emersa da Bacia de Campos. Embora seja alvo de estudos sedimentológicos e
estratigráficos desde a década de 1940, os estudos envolvendo amostragens de subsuperfície
contínuas e de alcance profundo são recentes e pouco numerosos. Com base nisto, o presente
trabalho busca contribuir através de informações litológicas, faciológicas e paleoambientais
advindas da testemunhagem contínua do poço 2-TO-1-RJ (181 m) e subsidiar discussões
acerca da evolução do CDRPS. Análises de difração de raios-X (DRX) em argilominerais, carbono
orgânico total (COT) e palinofácies foram realizadas para a caracterização dos paleoambientes
deposicionais. Datações por radiocarbono foram importantes para a correlação com os
modelos evolutivos existentes. Com o apoio de descrições petrográficas, foram identificadas
12 fácies sedimentares, dentre as quais uma rudítica (Ccm), cinco areníticas (ACm, Am, Amf, Ae
e ALm), uma heterolítica (IF), duas híbridas (Ab e Lh) e três lutíticas (Lm, LI e LAm), agrupadas
em sete sucessões de fácies (SF-LA, SF-F1, SF-Dc, SF-M, SF-F2, SF-Lg e SF-F3), indicativas
de diferentes estágios de sedimentação. Os resultados apontam para uma sedimentação basal
típica de porções medianas a distais de leques aluviais sucedida por deposição em ambiente
fluvial, ambos atribuídos ao Membro São Tomé (Formação Emborê). Estes depósitos foram
parcialmente erodidos pela escavação de um vale inciso, que, sob condições de criação de espaço
de acumulação, foi preenchido por sedimentos fluviais e estuarinos, de idade pleistocênica
(mais antigos que 40.000 anos AP), que, por sua vez, são sobrepostos por depósitos marinhos,
atribuídos ao máximo transgressivo de 123.000 anos AP. O registro holocênico é restrito aos
primeiros 13,40 m do testemunho e sugere a instalação de uma paleolaguna, posteriormente
colmatada por um sistema fluvial.

Palavras-chave. Porção emersa da Bacia de Campos, Fácies Sedimentares, Quaternário, Variações relativas do nível do mar

Abstract. FACIES AND PALEO-ENVIRONMENTS IN A STRATIGRAPHIC SUCCESSION OF PARAíBA DO Sul River Deltaic Complex central portion (RJ, Brazil). The Paraíba do Sul River Deltaic Complex (PSRDC), located on the northern coast of Rio de Janeiro, is an important Quaternary coastal plain that encompasses part of the Campos Basin onshore portion. Although it has been the subject of sedimentological and stratigraphic studies since the 1940s, the works involving continuous, deep-range subsurface sampling is recent and few in number. Based on this, this paper seeks to contribute through lithological, faciological and paleoenvironmental information from the continuous core sampling of 2-TO-1-RJ (181 m) well and to support discussions about the evolution of PSRDC. Analysis of X-rays diffraction (XRD) in clay minerals, total organic carbon (TOC) and palynofacies were performed for the characterization of depositional paleoenvironments. Radiocarbon dating was important for correlation with existing evolutionary models. With the support of petrographic descriptions, twelve sedimentary facies were identified, among them one conglomerate (Ccm), five sandstones (ACm, Am, Amf, Ae and ALm), one heterolithic (IF), two hybrids ( $A b$ and $L h$ ) and three mudstones ( $L m$, $L I$ and $L A m$ ), grouped in seven facies successions (SF-LA, SF-F1, SF-Dc, SF-M, SF F2, SF-Lg and SF F3), indicative of different stages of sedimentation. The results point to a basal sedimentation in a typical medium to distal portions of alluvial fans succeeded by deposition in the fluvial environment, both attributed to the São Tomé Member (Emborê Formation). These deposits were partially eroded by the excavation of an incised valley, which, under creation of space for sediment accumulation, was 
filled by fluvial and estuarine sediments, of Pleistocene age (older than 40,000 years BP), and overlapped by marine deposits, attributed to the transgressive maximum of 123,000 years BP. The Holocene record is restricted to the first $13.40 \mathrm{~m}$ of the drillcore and suggests the installation of a paleolagoon, filled by a fluvial system.

Keywords. Onshore Campos Basin, Sedimentary facies, Quaternary, Relative sea level variations

\section{Introdução}

Planícies costeiras são extensas áreas de terras baixas e planas situadas ao longo do litoral que abrigam uma ampla variedade de ambientes de sedimentação (deltas, rias, estuários, campo de dunas e manguezais, dentre outros), os quais tendem a preservar importantes registros referentes à evolução da paisagem (Boyd et al., 1992; Davies Jr. \& Fitzgerald, 2004; Boyd, 2010).

O conhecimento acerca das planícies costeiras brasileiras advém de mapeamentos geológicos, complementados por datações de ${ }^{14} \mathrm{C}$, estudos paleontológicos, sondagens rasas e levantamentos geofísicos de pequeno alcance (e.g. Ground Penetrating Radar - GPR), que permitiram um avanço significativo no entendimento das oscilações do nível do mar e, também, das variações climáticas ocorridas durante o Quaternário. Entretanto, são áreas que ainda carecem de dados de subsuperfície profundos, principalmente sondagens com amostragem contínua e levantamentos sísmicos, que permitem a realização de estudos sedimentológicos e estratigráficos ao longo de toda a sucessão sedimentar.

Neste contexto, destaca-se o Complexo Deltaico do Rio Paraíba do Sul (CDRPS), uma ampla planície costeira de idade quaternária localizada no litoral norte do Estado do Rio de Janeiro. Os estudos pioneiros realizados na área do CDRPS (e.g. Lamego, 1944; 1955; Bacoccoli, 1971; Araújo \& Beurlen, 1975; Martin et al., 1984; 1993; 1997; Silva, 1987; Dominguez, 1990) basearam-se exclusivamente em informações de superfície, advindas de mapeamentos geológicos e geomorfológicos, e algumas poucas sondagens rasas (<30 $\mathrm{m}$ de profundidade). Dados de subsuperfície profundos constituíamse apenas de um testemunho com amostragem descontínua (2-CST-1-RJ), alguns poucos perfis de poços e seções sísmicas executadas próximas ao litoral (Schaller, 1973; Gama Jr., 1977), que não foram considerados em nenhum dos modelos evolutivos propostos.

Pesquisas recentes realizadas na área do CDRPS a partir de testemunhos contínuos (Vilela et al., 2016; Plantz et al., 2018) revelaram uma grande variação litológica e paleoambiental entre as suas porções sul e central, indicando uma evolução mais complexa do que o historicamente proposto para a região. A ocorrência de fácies heterolíticas e híbridas (mistura entre sedimentos siliciclásticos e carbonáticos de origem distintas), associadas a depósitos de planície de maré e marinho-lagunar de idade pleistocênica (Gatto, 2016; Plantz et al., 2018), reportadas apenas para a porção central do CDRPS, caracterizada geomorfologicamente como uma extensa planície fluvio-lagunar holocênica (Martin et al., 1993), fomenta novas pesquisas na região.

A possibilidade de estudo sedimentológico, sob enfoque da análise de fácies, de um testemunho contínuo e profundo (181 m) localizado na porção central da planície costeira do CDRPS, a aproximadamente $15 \mathrm{~km}$ à NW do testemunho analisado por Plantz et al. (2018), permitecomplementare expandiro conhecimento da região e abre uma nova oportunidade para a discussão da evolução paleoambiental do CDRPS através da interpretação estratigráfica das sucessões de fácies identificadas, o que constitui o objetivo deste trabalho.

\section{2 Área de estudo, material e métodos}

\section{1 Localização da área e contextualização geológica}

O Complexo Deltaico do Rio Paraíba do Sul, localizado no litoral norte do Estado do Rio de Janeiro, apresenta uma superfície de aproximadamente $3.000 \mathrm{~km}^{2}$, possuindo $120 \mathrm{~km}$ 
de comprimento na direção Norte-Sul e largura máxima de $60 \mathrm{~km}$. A área é recoberta por sedimentos marinhos, parálicos e continentais de idade pleistocênica-holocênica, abrangendo parte da porção emersa da Bacia de Campos.

Foram registradas em subsuperfície, na região mais próxima ao litoral do CDRPS, onde além do poço 2-CST-1-RJ, há seções sísmicas, rochas gnáissicas do embasamento pré-cambriano, bem como rochas vulcânicas eocretácicas (Formação Cabiúnas), rochas sedimentares neocretácicas e depósitos cenozoicos, associados à evolução da porção emersa da Bacia de Campos (Lopes, 2004; Lana, 2011; Oliveira, 2015).

A espessa seção cenozoica da porção emersa da Bacia de Campos é constituída por: (i) depósitos areno-lamosos conglomeráticos de coloração cinza-esverdeada dos sistemas de leques aluviais e fluviais do Membro São Tomé (Formação Emborê), não aflorante, de idade oligocênica-pliocênica (Schaller, 1973; Gama Jr., 1977; Vilela et al., 2016); (ii) arenitos e arenitos lamosos intercalados com lamitos e conglomerados, normalmente oxidados, por vezes ferruginizados, relacionados a ambiente fluvial entrelaçado de alta energia, com contribuição de fluxos gravitacionais atribuídos à Formação Barreiras (Morais, 2001; Brêda, 2012; Vilela et al., 2016), cuja idade atualmente aceita está compreendida entre o Mioceno e o Plioceno (Suguio \& Nogueira, 1999); e (iii) depósitos quaternários que se encontram intimamente associados à construção e evolução do CDRPS.

$$
\text { A sedimentação quaternária }
$$

historicamente descrita para o CDRPS inclui: (i) terraços marinhos pleistocênicos constituídos por alinhamentos de cordões arenosos brancos em superfície e acastanhados em profundidade, com estratificação de ângulo baixo, encontrados preferencialmente ao sul do Cabo de São Tomé; (ii) terraços marinhos holocênicos constituídos por alinhamentos de cordões arenosos brancos, podendo conter grandes quantidades de conchas, situados ao norte, próximos à desembocadura do Rio Paraíba do Sul; e (iii) depósitos aluviais e coluviais holocênicos, que correspondem a sedimentos areno-síltico-argilosos bem desenvolvidos em vales fluviais, e depósitos lagunares holocênicos, que correspondem a sedimentos sílticos/areno-argilosos ricos em matéria orgânica, podendo conter conchas de moluscos. Estes depósitos possuem maior abrangência na porção central do CDRPS e separam os terraços arenosos pleistocênicos dos terraços holocênicos (Silva, 1987; Martin et al., 1997; Rocha et al., 2013; Fig. 1).

Destoando do proposto através de mapeamentos geológicos, dados de subsuperfície adquiridos recentemente (q.v. Vilela et al., 2016; Plantz et al., 2018) mostram uma grande diversidade litológica e de ambientes de sedimentação associados a construção do CDRPS. A sedimentação quaternária da porção central do CDRPS, objeto do presente estudo, engloba rochas com acamamento heterolítico e rochas híbridas (termo usado para descrever rochas caracterizadas pela mistura entre sedimentos siliciclásticos e carbonáticos, incluindo bioclastos diversos, nano- e microfósseis calcários), interpretadas como parte de uma sedimentação estuarina sucedida por um ambiente marinho franco (desconfinado) com posterior instalação de uma paleolaguna (c.f. Plantz et al., 2018). A estes depósitos foi atribuída uma idade pleistocênica (Gatto, 2016; Plantz et al., 2018) e, os mesmos, associados ao registro da transgressão de 123.000 anos $A P$, através da qual se iniciou a construção e evolução da área de estudo (Plantz et al., 2018).

\subsection{Material de estudo}

o material de estudo consiste do testemunho de sondagem do poço 2-TO-1-RJ (coordenadas geográficas: $21^{\circ} 51^{\prime} 33,36 " \mathrm{~S} / 41^{\circ} 16^{\prime} 05,61^{\prime \prime}$ W, datum WGS 84), localizado no distrito de Tócos, Município de Campos dos Goytacazes, Estado do Rio de Janeiro (Fig. 1). A sondagem alcançou $181 \mathrm{~m}$ de profundidade, atingindo o embasamento cristalino em torno de 173 m, com recuperação aproximada de 83\% ( $150 \mathrm{~m})$.

\subsection{Métodos de análise}

O testemunho do poço 2-TO-1-RJ (Tócos) foi descrito em escala de detalhe (1:40), 


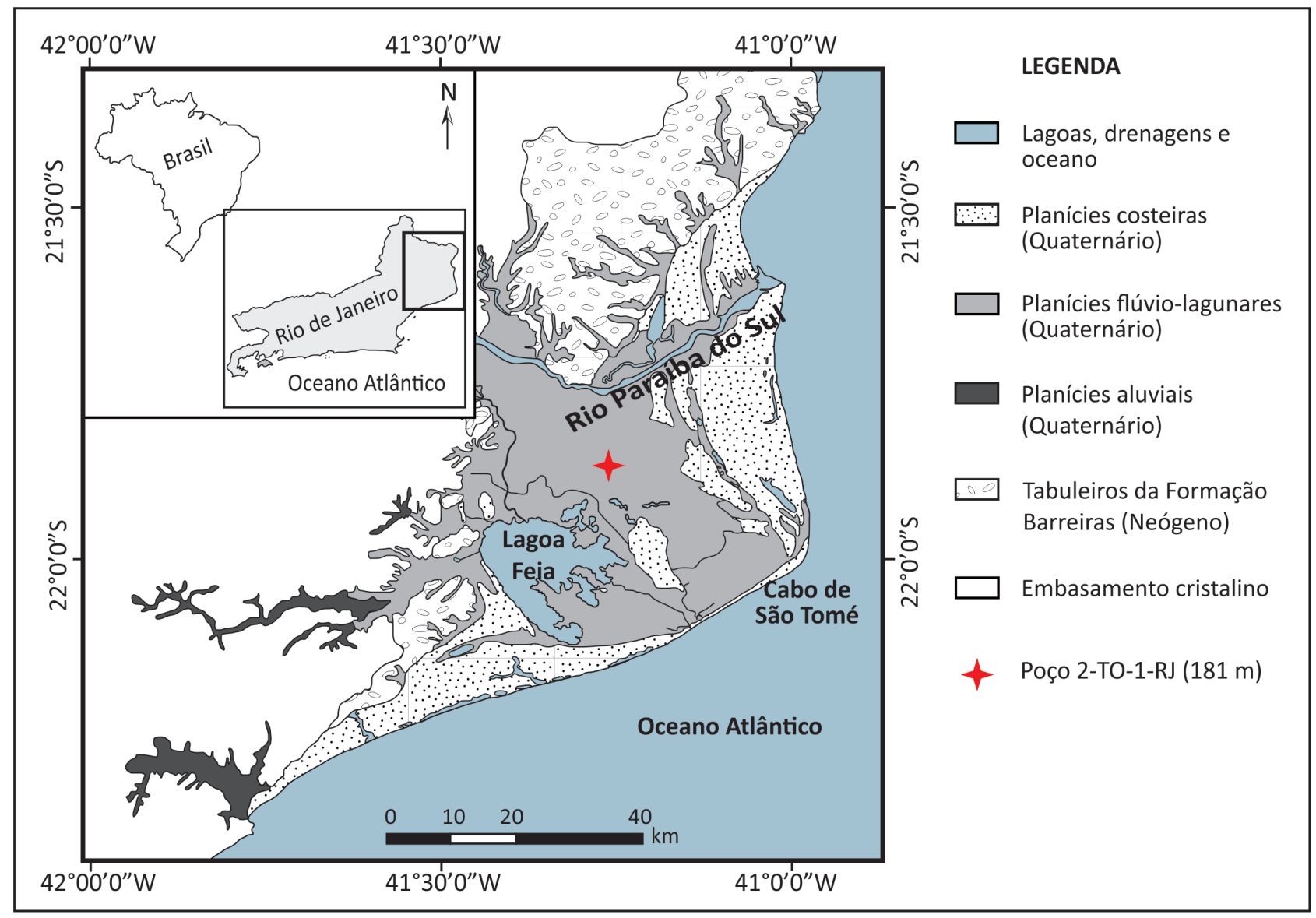

Figura 1. Mapa de localização do poço 2-TO-1-RJ (Tócos) na porção central do Complexo Deltaico do Rio Paraíba do Sul (CDRPS), com indicação das rochas e depósitos presentes no CDRPS e áreas adjacentes (modificado de Silva \& Cunha, 2001).

Figure 1. Location map of the 2-TO-1-RJ (Tócos) well in the central portion of Paraiba do Sul River Deltaic Complex (PSRDC), with indication of the rocks and deposits present in PSRDC and adjacent areas (modified from Silva \& Cunha, 2001).

baseado na proposta de Selley (1968), levando em consideração litologias, aspectos texturais (granulometria, seleção, arredondamento dos grãos e argilosidade), composição (mineralogia), estruturas sedimentares, fósseis (bioclastos) e cores. A descrição foi feita com o auxílio de estereomicroscópio (modelo Carl ZEISS Stemi 2000-C) e de um conjunto de peneiras (com aberturas de 2,00; 1,00; 0,50; 0,25; 0,1 25 e 0,062 $\mathrm{mm}$ ) que permitiram a identificação expedita dos aspectos texturais.

Para complementar a descrição foram realizadas: (i) análises granulométricas em 82 amostras através do método de tamisação e pipetagem (sensu Folk, 1954; 1968); e (ii) imageamento por raio- $X$ em seis amostras através do equipamento de raio- $X$ Yxlon, modelo Y.TU160-D05 do Laboratório de Instrumentação Nuclear (LIN) da Universidade Federal do Rio de Janeiro (UFRJ). As imagens foram processadas no software Ic vision $10.2 \AA$ para destacar as variações de densidade e auxiliar a identificação de estruturas sedimentares.

A partir da descrição, análises granulométricas e imageamento por raio- $X$, foi elaborado um perfil estratigráfico simplificado (escala 1:800) no software CorelDraw ${ }^{\circledR}$ (Fig. 2) que auxiliou na identificação das fácies e sucessões de fácies. As fácies sedimentares foram definidas segundo os critérios de Borghi (2000) e apoiadas por descrições petrográficas qualitativas em 20 lâminas delgadas realizadas por meio de microscópio petrográfico de luz transmitida / polarizada, modelo Carl ZEISS Axio Imager A2m. As fácies foram interpretadas em termos de processos deposicionais, e, posteriormente, agrupadas em sucessões de fácies para a interpretação paleoambiental.

Para auxiliar na interpretação e caracterização paleoambiental, foram realizadas 
análises de: (i) difração de raios-X (DRX) de argilominerais em sete amostras; (ii) carbono orgânico total em razão com enxofre (COT/S) em 25 amostras; e (iii) palinofácies em 26 amostras.

As análises de DRX foram realizadas através do equipamento Bruker-D4 Endeavor no Centro de Tecnologia Mineral (CETEM) e as interpretações qualitativas do espectro determinadas por comparação com padrões contidos no banco de dados do CETEM.

As determinações do carbono orgânico total (\% COT) e do enxofre (\% S) foram realizadas utilizando o equipamento SC 144 da LECO pertencente ao Laboratório de Palinofácies e Fácies Orgânicas (LAFO) da UFRJ. A partir dos valores de COT e $S$ obteve-se a razão COT/S, importante indicadora de condições físico-químicas do ambiente que, quando $>3$ indica condições oxidantes e quando $<3$ indica condições redutoras (Bernner, 1995; Borrego et al., 1998).

A preparação de amostras para identificação das partículas orgânicas eanálise de palinofácies seguiu o método descrito por Tyson (1995) e Mendonça Filho et al. (2010). As lâminas palinológicas foram analisadas quantitativa e qualitativamente através do microscópio Carl ZEISS Axioskop 40 em luz transmitida e fluorescente. Foi feita a contagem de 300 pontos e o agrupamento da matéria orgânica particulada (MOP) em quatro associações de palinofácies (palinomorfos aquáticos, palinomorfos terrestres, fitoclastos não-opacos e matéria orgânica amorfa).

Datações por radiocarbono $\left({ }^{14} \mathrm{C}\right)$ foram realizadas em duas amostras por meio de espectrometria de massa com aceleradores (método AMS - Accelerator Mass Spectrometry) no Laboratório Beta Analytic Inc. para contextualização cronoestratigráfica.

\section{Resultados}

A partir das análises granulométricas e da classificação proposta por Folk (1954), afirmase que no testemunho do poço 2-TO-1-RJ predominam rochas essencialmente arenosas, sendo muito frequente a ocorrência de rochas arenosas com contribuição de finos maior que
10\%, classificadas como arenitos lamosos (Fig. 3). A proporção de grânulos e seixos (cascalho) é relativamente baixa, sendo que as maiores concentrações encontram-se na porção basal do testemunho (entre 173,00 m e 137,60 m) e apenas a amostra de 99,10 m pôde ser classificada como um conglomerado (cascalho arenoso, segundo Folk, 1954) que, por definição, deve apresentar proporção de cascalho superior a $30 \%$.

As amostras com mais de $50 \%$ de finos são classificadas como lamitos arenosos (50-90\% de finos) e lamitos (> 90\% de finos) e ocorrem em três intervalos bem marcados $(21,20-33,40 \mathrm{~m}$; 47,80-84,10 m e 129,60-137,20 m).

Baseado em aspectos texturais e composicionais, a seção sedimentar do testemunho do poço 2-TO-1-RJ pode ser dividida em quatro intervalos que guardam relação com as sucessões de fácies definidas neste estudo. O primeiro intervalo (172,70-137,60 m), disposto sobre o embasamento, é caracterizado por arenitos e arenitos lamosos maciços, ricos em grânulos, compostos essencialmente por quartzo e feldspato, que ocorrem associados a arenitos conglomeráticos maciços e delgadas camadas delamitos elamitos arenosos maciços; o segundo (137,60-84,10 m), caracteriza-se pela presença de lamitos e lamitos arenosos maciços sobrepostos por areias, arenitos e arenitos lamosos, por vezes com estratificação, normalmente grossos, ricos em grânulos e oxidados; no terceiro (84,1047,80 m) ocorre quase que exclusivamente lamitos de coloração cinza escuro e ricos em detritos vegetais; já o quarto (47,80-0,00 m) é caracterizado pela presença de lamitos maciços oxidados sobrepostos por areias e arenitos de composição essencialmente quartzosa, por vezes, lamitos e areia/arenito apresentam conchas bem preservadas.

A porção basal do testemunho (181$172,70 \mathrm{~m})$ é caracterizada por rochas granitognáissicas do embasamento cristalino que apresentam foliação marcada pela orientação dos minerais máficos, normalmente encontramse cortadas por diques graníticos e, por vezes, milonitizadas e com estruturas indicadoras de deformação em zona de cisalhamento (sigmas, deltas e dobras incipientes). 


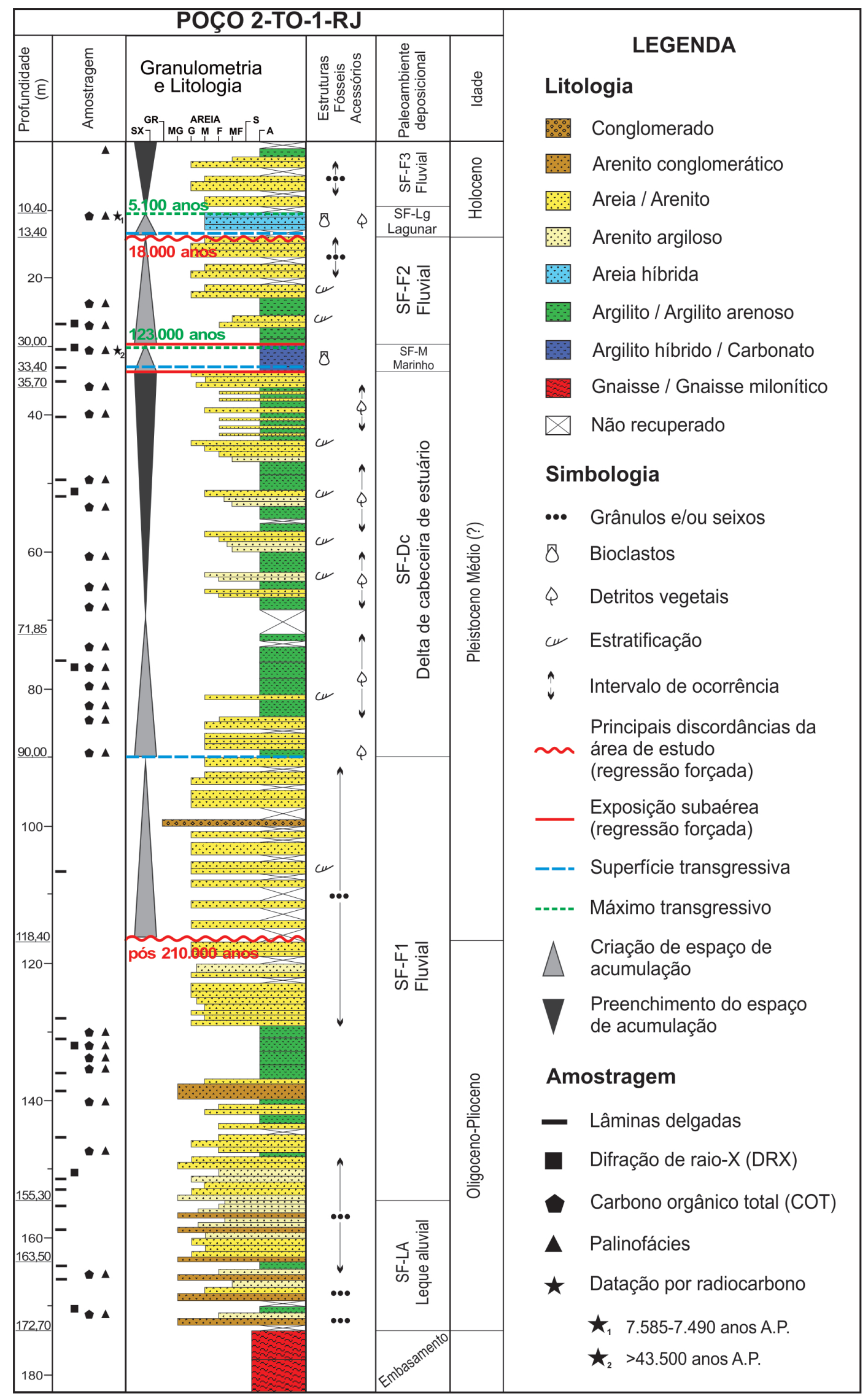

Figura 2. Perfil estratigráfico simplificado do testemunho do poço 2-TO-1-RJ (escala 1:800), com destaque para as sucessões de fácies e paleoambientes deposicionais interpretados. Notar a posição das amostras coletadas para análises laboratoriais e as principais superfícies estratigráficas.

Figure 2. Simplified stratigraphic profile of the drillcore 2-TO-1-RJ (scale 1:800), emphasize the facies succession and depositional paleoenvironments interpreted. Note the position of the collected samples for laboratory analysis and the main stratigraphic surfaces. 


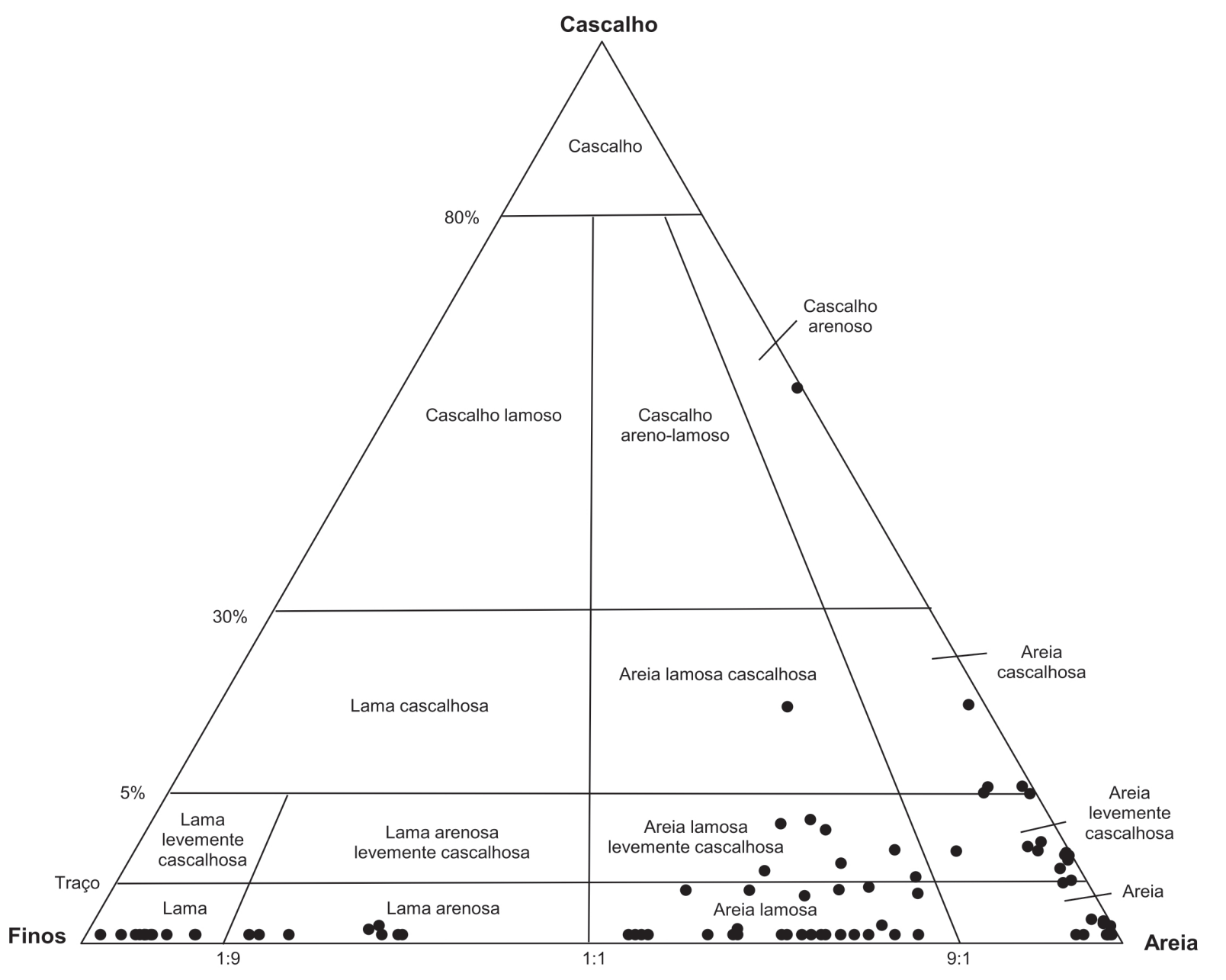

Figura 3. Diagrama ternário de Folk (1954) com a classificação textural das amostras coletadas para análise granulométrica ao longo do testemunho do poço 2-TO-1-RJ.

Figure 3. Ternary diagram of Folk (1954) with textural classification of the samples collected for grain size analysis along the drillcore 2-TO-1-RJ.

\subsection{Fácies sedimentares e sucessões de fácies}

Doze fácies sedimentares foram descritas para o testemunho do poço 2-TO-1-RJ, dentre as quais uma rudítica (Ccm), cinco areníticas (ACm, Am, Amf, Ae e ALm), uma heterolítica (IF), duas híbridas (Ab e Lh) e três lutíticas ( $L m, \mathrm{LI}$ e LAm), sintetizadas no quadro 1. De acordo com o padrão de empilhamento sedimentar e a relação de fácies, foram caracterizadas sete sucessões de fácies (SF-LA, SF-F1, SF-Dc, SF-M, SF-F2, SF-Lg e SF-F3), que representam diferentes estágios de sedimentação no CDRPS (Fig. 2).

\subsubsection{Sucessão de fácies LA (SF-LA)}

A SF-LA ocorre entre 172,70 m e 155,30 m de profundidade, em contato difuso com o topo do embasamento cristalino (Fig. 2), sendo caracterizada por depósitos maciços, com indícios de atuação de processos pedogenéticos (oxidação, argila infiltrada e dissolução), baixo grau de seleção, composição arcoseana e coloração cinza-esverdeada (Figs. 4 e 5). É constituída pelas fácies ACm, ALm, Am e LAm (Quadro 1), organizadas em ciclos métricos de afinamento granulométrico para o topo (finning upward). A base dos ciclos é definida por arenitos muito grossos a grossos, conglomeráticos (fácies ACm - Fig. 4A) sucedidos por arenitos lamosos (fácies ALm - Fig. 4B) e/ou por arenitos (fácies Am), cuja granulometria diminui para o topo. Na porção basal da SF-LA (172,70163,50 m - Fig. 2), camadas centimétricas de lamitos arenosos (fácies LAm - Fig. 4C) frequentemente recobrem os arenitos e arenitos 
Quadro 1. Síntese das fácies sedimentares descritas para o testemunho do poço 2 TO 1 RJ. Chart 1. Synthesis of the sedimentary facies described for the drillcore 2-TO-1-RJ.

\begin{tabular}{|c|c|c|c|c|}
\hline & CÓDIGO & DIAGNOSE & DESCRIÇÃO & INTERPRETAÇÃO \\
\hline 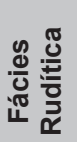 & $\mathrm{Ccm}$ & $\begin{array}{l}\text { Conglomerado } \\
\text { sustentado pelos } \\
\text { clastos maciço }\end{array}$ & $\begin{array}{l}\text { Conglomerado fino sustentado pelos clastos, maciço, } \\
\text { constituído essencialmente por grânulos e seixos } \\
\text { subangulosos a subarredondados de quartzo e feldspato. } \\
\text { Argilosidade inferior a } 10 \% \text { e coloração acinzentada }\end{array}$ & $\begin{array}{l}\text { Fluxo trativo } \\
\text { subaquoso de alta } \\
\text { energia }\end{array}$ \\
\hline \multirow{5}{*}{ 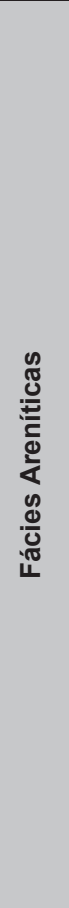 } & $\mathrm{ACm}$ & $\begin{array}{l}\text { Arenito } \\
\text { conglomerático } \\
\text { maciço }\end{array}$ & $\begin{array}{l}\text { Arenito conglomerático maciço, feldspático, muito grosso, } \\
\text { anguloso, mal selecionado. Grânulos e seixos são } \\
\text { abundantes, litoclastos graníticos podem estar presentes. } \\
\text { Argilosidade inferior a } 25 \% \text { e coloração acinzentada, } \\
\text { podendo conter manchas amareladas. Por vezes, os } \\
\text { grãos apresentam sutil alinhamento sugerindo a presença } \\
\text { de estratificação. }\end{array}$ & $\begin{array}{l}\text { Fluxo trativo } \\
\text { subaquoso de alta } \\
\text { energia }\end{array}$ \\
\hline & $\mathrm{Am}$ & $\begin{array}{l}\text { Arenito maciço } \\
\text { com alteração } \\
\text { pós-deposicional }\end{array}$ & $\begin{array}{l}\text { Arenito e arenito argiloso maciço ou sem estrutura } \\
\text { aparente, quartzoso, fino a grosso, subanguloso, } \\
\text { moderado a mal selecionado. Grânulos e seixos, marcas } \\
\text { de raízes e bioturbações podem estar presentes. } \\
\text { Argilosidade inferior a } 30 \% \text { e coloração principal é } \\
\text { amarelada }\end{array}$ & $\begin{array}{l}\text { Modificação pós- } \\
\text { deposicional de } \\
\text { depósitos gerados por } \\
\text { fluxo trativo subaquoso }\end{array}$ \\
\hline & Amf & $\begin{array}{l}\text { Areia micácea } \\
\text { e/ou feldspática }\end{array}$ & $\begin{array}{l}\text { Areia (material inconsolidado) micácea e/ou feldspática, } \\
\text { fina a grossa, subangulosa, moderada a mal selecionada. } \\
\text { Grânulos podem estar presentes. Argilosidade inferior a } \\
5 \% \text { e coloração levemente amarronzada / amarelada }\end{array}$ & $\begin{array}{l}\text { Fluxo trativo } \\
\text { subaquoso }\end{array}$ \\
\hline & $\mathrm{Ae}$ & $\begin{array}{l}\text { Arenito } \\
\text { estratificado }\end{array}$ & $\begin{array}{l}\text { Arenito e arenito argiloso estratificado, feldspático, muito } \\
\text { fino a grosso, subanguloso, moderado a mal selecionado. } \\
\text { Grânulos e seixos, intraclastos e detritos vegetais podem } \\
\text { estar presentes. Argilosidade inferior a } 30 \% \text { e coloração } \\
\text { acinzentada }\end{array}$ & $\begin{array}{l}\text { Fluxo trativo } \\
\text { unidirecional } \\
\text { subaquoso, associoado } \\
\text { a migração de } \\
\text { megaondulações }\end{array}$ \\
\hline & ALm & $\begin{array}{l}\text { Arenito lamoso } \\
\text { maciço }\end{array}$ & $\begin{array}{l}\text { Arenito lamoso maciço, feldspático, fino a grosso, por } \\
\text { vezes conglomerático, anguloso, mal selecionado. } \\
\text { Grânulos e seixos sempre presentes. Argilosidade } \\
\text { superior a } 30 \% \text { e coloração cinza-esverdeada }\end{array}$ & $\begin{array}{l}\text { Fluxo de detritos de } \\
\text { moderada a baixa } \\
\text { energia }\end{array}$ \\
\hline 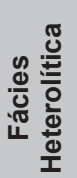 & IF & $\begin{array}{l}\text { Intercalações } \\
\text { entre argilito e } \\
\text { arenito ricos em } \\
\text { fitoclastos }\end{array}$ & $\begin{array}{l}\text { Intercalações entre argilito e arenito fino subanguloso, } \\
\text { constituindo acamamento heterolítico lenticular, por vezes } \\
\text { bioturbado e com abundantes detritos vegetais. } \\
\text { Argilosidade varia entre } 60 \text { e } 70 \% \text { e coloração } \\
\text { acinzentada / amarronzada. }\end{array}$ & $\begin{array}{l}\text { Alternância entre } \\
\text { decantação de finos e } \\
\text { eventos esporádicos de } \\
\text { fluxo trativo subaquoso. }\end{array}$ \\
\hline \multirow{2}{*}{ 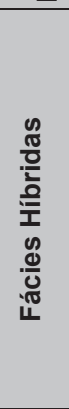 } & $A b$ & $\begin{array}{l}\text { Areia rica em } \\
\text { bioclastos }\end{array}$ & $\begin{array}{l}\text { Areia (material inconsolidado) quartzosa, média, } \\
\text { subangulosa, moderada a mal selecionada, rica em } \\
\text { bioclastos fragmentados (conchas de bivalves e de } \\
\text { gastrópodes da espécie Heleobia australis com bioerosão) } \\
\text { e detritos vegetais. Argilosidade inferior a } 25 \% \text { e coloração } \\
\text { cinza escura }\end{array}$ & $\begin{array}{l}\text { Alternância entre fluxo } \\
\text { trativo subaquoso e } \\
\text { decantação, seguido } \\
\text { de reelaboração } \\
\text { biogênica }\end{array}$ \\
\hline & Lh & $\begin{array}{l}\text { Lamito híbrido rico } \\
\text { em bioclastos }\end{array}$ & $\begin{array}{l}\text { Lamito híbrido maciço, com elevada proporção de material } \\
\text { carbonático ( } 75-85 \%) \text {. Abundante matriz margosa rica em } \\
\text { nanofósseis calcários e bioclastos diversos (foraminíferos, } \\
\text { bivalves, equinoides, moluscos). Argilosidade superior a } \\
80 \% \text { e coloração cinza-esverdeada, com tons amarelados }\end{array}$ & $\begin{array}{l}\text { Decantação de finos } \\
\text { (siliciclásticos e } \\
\text { carbonáticos) em } \\
\text { suspensão, seguido de } \\
\text { alteração pós- } \\
\text { deposicional }\end{array}$ \\
\hline \multirow{3}{*}{ 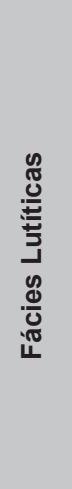 } & $\mathrm{Lm}$ & $\begin{array}{l}\text { Lamito maciço } \\
\text { com alteração } \\
\text { pós-deposicional }\end{array}$ & $\begin{array}{l}\text { Lamito maciço, por vezes micáceo, frequentemente } \\
\text { bioturbado. Argilosidade superior a } 70 \% \text {, fração arenosa é } \\
\text { rara. Coloração varia em tons amarronzados, } \\
\text { acinzentados e esverdeados, contudo tons amarelados } \\
\text { estão sempre presentes }\end{array}$ & $\begin{array}{l}\text { Decantação rápida de } \\
\text { carga em suspensão, } \\
\text { seguido de alteração } \\
\text { pós-deposicional }\end{array}$ \\
\hline & $\mathrm{LI}$ & Lamito laminado & $\begin{array}{l}\text { Lamito laminado, por vezes micáceo, raramente } \\
\text { bioturbado, rico em detritos vegetais. Argilosidade superior } \\
\text { a } 80 \% \text {, fração arenosa ocorre em níveis bem marcados. } \\
\text { Coloração predominantemente cinza escura }\end{array}$ & $\begin{array}{l}\text { Alternância entre } \\
\text { decantação de finos } \\
\text { em suspensão e fluxos } \\
\text { trativos subaquosos. }\end{array}$ \\
\hline & LAm & $\begin{array}{l}\text { Lamito arenoso } \\
\text { maciço }\end{array}$ & $\begin{array}{l}\text { Lamito arenoso maciço, moderado a mal selecionado. } \\
\text { Fração arenosa grossa a muito fina, grânulos e seixos } \\
\text { ocorrem em proporções relativamente elevadas. } \\
\text { Argilosidade varia entre } 55 \text { e } 70 \% \text { e coloração cinza- } \\
\text { esverdeada, com tons amarelados presentes }\end{array}$ & $\begin{array}{l}\text { Fluxo de detritos de } \\
\text { moderada a baixa } \\
\text { energia (corridas de } \\
\text { lama) }\end{array}$ \\
\hline
\end{tabular}




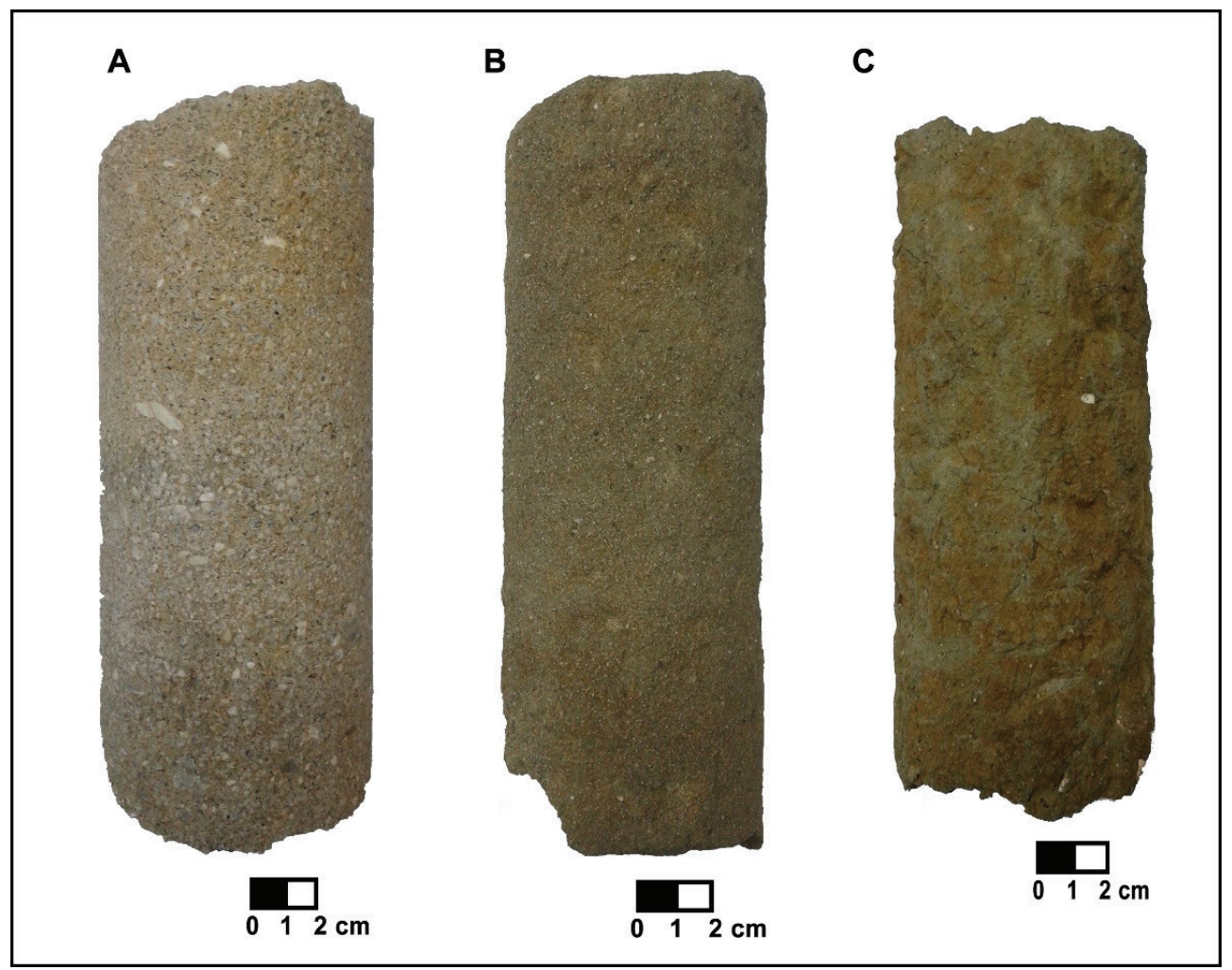

Figura 4. Fácies típicas da SF-LA interpretada como porções medianas a distais de leques aluviais. A) Fácies ACm; B) Fácies ALm; C) Fácies LAm. Notar o aspecto maciço e a coloração cinza-esverdeada, com manchas de oxidação atribuídas a alterações pós deposicionais.

Figure 4. Facies typical of the SF-LA interpreted as medial to distal portions of aluvial fans. A) Facies ACm; B) Facies $A L m ; C)$ Facies LAm. Note the massive appearance and grayish-green coloration with oxidation spots attributed to postdepositional changes.

lamosos, estando presentes no topo dos ciclos.

$\mathrm{O}$ intervalo correspondente a SF-LA apresenta uma tendência de diminuição da variedade de minerais pesados em direção ao topo, em sua porção basal (172,70-163,50 m) há rutilo, turmalina, granada, monazita e zircão, dentre outros, enquanto no topo (163,50-155,30 m) observa-se apenas zircão e rutilo. A mudança na assembleia mineralógica eno padrão de empilhamento sedimentar observada entre a porção basal (172,70-163,50 m) e o topo (163,50-155,30 m - Fig. 2) da SF-LA pode ser associada a uma fase de reativação tectônica, responsável pelo soerguimento da área-fonte, e consequentemente pela progradação do sistema, predominando condições de maior energia no topo da sucessão, e, também, pela proveniência sedimentar.Os depósitos e o padrão de empilhamento descrito para a SFLA correspondem a porções medianas a distais de leques aluviais, onde, além da contribuição de fluxos de detritos e de corridas de lama, os lobos dos leques estariam retrabalhados por correntes preferencialmente desconfinadas, em um modelo de canais rasos e efêmeros, similares aos canais entrelaçados de Miall (1996), por isso, a recorrência de depósitos associados a fluxos trativos.

\subsubsection{Sucessão de fácies F1 (SF-F1)}

A SF-F1 ocorre entre 155,30 m e 90,00 m de profundidade, em contato transicional com o topo da SF-LA (Fig. 2), englobando as fácies Ccm, ACm, Am, Amf, Ae, LAm e Lm (Quadro 1). De modo geral, a sucessão é caracterizada por arenitos maciços e areias, ambos com indícios de atuação de processos pedogenéticos, principalmente oxidação, o que sugere longos períodos de exposição subáerea causados por superfícies de interrupção da sedimentação (hiatos). No caso dos arenitos, a oxidação confere aspecto mosqueado a rocha, dificultando a identificação de estruturas sedimentares. 


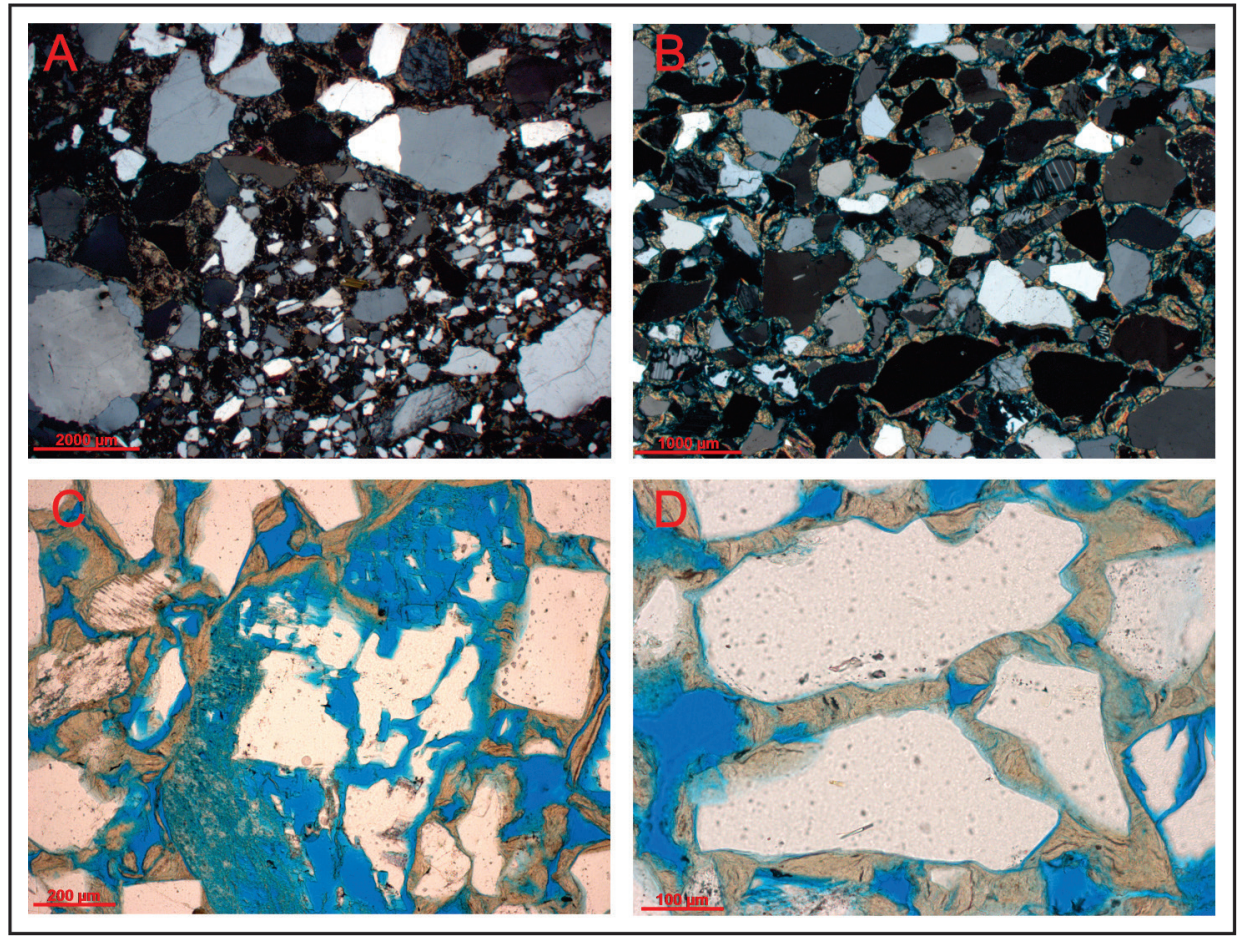

Figura 5. Aspectos petrográficos da SF-LA. A) Notar o baixo grau de seleção e o aspecto maciço (158,50 m/polarizadores cruzados); B) Notar elevada proporção de feldspatos (ortoclásio, microclínio e plagioclásio - 163,00 m/polarizadores cruzados); C) Notar argila infiltrada preenchendo porosidade primária e porosidade secundária dada por dissolução de ortoclásio e quartzo (165,40m/polarizadores paralelos); D) Em detalhe pontes de argila infiltrada preenchendo poros primários (165,40m/polarizadores paralelos).

Figure 5. Petrographic features of the SF-LA. A) Note the low degree of selection and the massive appearance (158.50 $\mathrm{m} /$ cross polarizers); $B$ ) Note the high proportion of feldspar (orthoclase, microcline and plagioclase - $163.00 \mathrm{~m} / \mathrm{cross}$ polarizers); C) Note the infiltrated clay filling primary porosity, and secondary porosity given by orthoclase and quartz dissolution (165.40 m/parallel polarizers); D) In detail, bridges of infiltrated clay filling primary pores (165.40m/parallel polarizers).

A porção inferior da SF-F1 (155,30118,40 m - Fig. 2) é caracterizada por empilhamentos de arenitos ferruginizados (Figs. 6A, 7A e 7B), normalmente grossos e médios, mal selecionados, subangulosos, compostos essencialmente por quartzo (fácies Am). O elevado grau de alteração pós-deposicional impede a identificação de estruturas sedimentares; contudo grãos sutilmente alinhados, sugerindo a presença de estruturas incipientes, puderam ser observados através de imageamento por raio- $X$ (Fig. 6) e indicam deposição através de fluxos trativos unidirecionais. Camadas centimétricas de arenitos conglomeráticos maciços (fácies $\mathrm{ACm})$, evidenciando períodos de maior energia, onde se dá o início de um novo ciclo de empilhamento de arenitos, bem como lamitos maciços ferruginizados, bioturbados e com marcas de raízes (fácies Lm - Fig. 7C) e lamitos arenosos maciços (fácies LAm - Fig. 7D) podem estar presentes.

As características texturais, o padrão de empilhamento sedimentar e os processos interpretados sugerem deposição em paleoambiente fluvial entrelaçado, com contribuição de fluxos gravitacionais. De acordo com Miall (1996), o aporte de finos neste estilo fluvial advém de decantação em canais abandonados, com posterior atuação de processos pedogenéticos (fácies Lm) e, principalmente, de corridas de lama (fácies LAm).

A porção superior (118,40-90,00 m Fig. 2) é caracterizada por depósitos arenosos inconsolidados. Nota-se um amplo predomínio de areias grossas e médias, ricas em grânulos, subangulosas, mal selecionadas e de composição quartzo-feldspática (fácies Amf). Camada centimétrica de conglomerado fino sustentado 
pelos clastos (fácies $\mathrm{Ccm}$ ) marca período de maior energia no sistema.

Devido à ausência de estruturas sedimentares, que conferem informações relevantes em relação ao processo gerador da fácies e ao paleoambiente deposicional, as interpretações foram feitas a partir das características texturais e composicionais dos sedimentos e do padrão de empilhamento, indicativos de deposição próxima à área-fonte, com pouco retrabalhamento, em ambiente fluvial de alta energia.

Destaca-se que os sedimentos inconsolidados que caracterizam a porção superior da SF-F1 estão dispostos sobre camadas de arenitos intensamente oxidados, com feições pedogenéticas. Este contato nítido sugere a existência de uma superfície de exposição subaérea dada pela queda do nível de base (regressão forçada) e marca uma importante discordância (Fig. 2).

\subsubsection{Sucessão de fácies Dc (SF-Dc)}

A SF-Dc ocorre entre 90,00 m e 33,40 m de profundidade (Fig. 2), onde é caracterizada por espessas camadas de lamitos laminados ricos em detritos vegetais (fácies $\mathrm{LI}$ - Figs. 8A e 9A; Quadro 1), arenitos maciços (fácies Am Quadro 1) e estratificados (fácies Ae - Fig. 8B; Quadro 1) médios a muito finos formando ciclos centimétricos a métricos de engrossamento granulométrico para o topo (coarsening upward), além de intercalações entre argilitos e arenitos, constituindo acamamento heterolítico lenticular (fácies IF - Figs. 8C e 9B; Quadro 1), restritos ao topo da sucessão.

A sedimentação essencialmente lamosa e a presença de bioclastos silicosos (radiolários?) na porção basal da sucessão (90,00-71,85 m) marca o início de uma transgressão marinha (Fig. 2). Segundo Campbell (1954), apesar de poucas formas de radiolários apresentarem
A

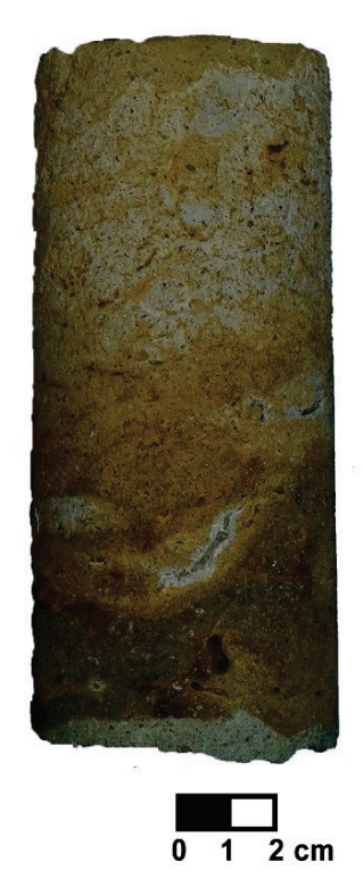

B

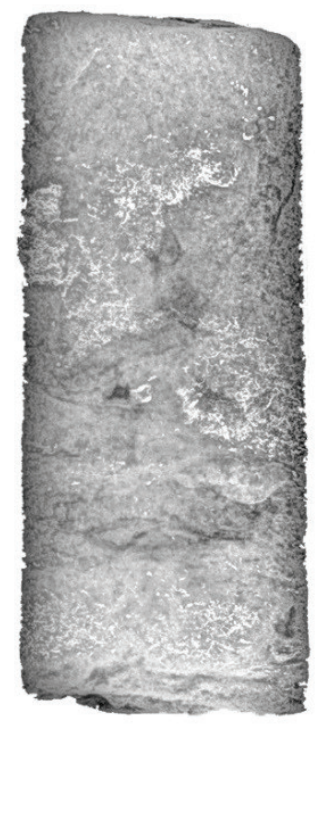

C

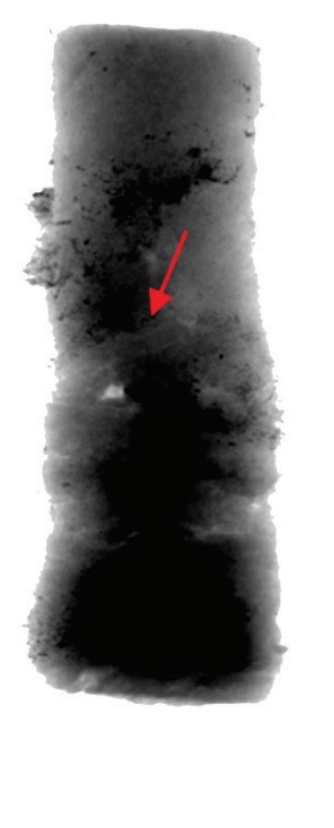

Figura 6. Imageamento por raio-x. A) Arenito médio, mal selecionado, com modificações pós deposicionais, incluindo ferruginização, da fácies Am, característico da porção inferior da SF-F1 (planície fluvial); B) Filtro de realce de detalhes mostrando aspecto predominantemente maciço; C) Filtros de contraste e de brilho mostrando uma incipiente orientação dos grãos (seta vermelha), sugerindo a presença de estratificação cruzada e, consequentemente, deposição através de fluxo trativo.

Figure 6. X-ray imaging. A) Medium sandstone, poorly selected, with post-depositional modifications, including ferruginization (facies Am) characteristic of SF-F1 lower portion (fluvial plain); B) Detail enhancement filter showing predominantly massive appearance; C) Contrast and gloss filters showing an incipient orientation of the grains (red arrow), suggesting cross stratification and, consequently, deposition through trative flow. 


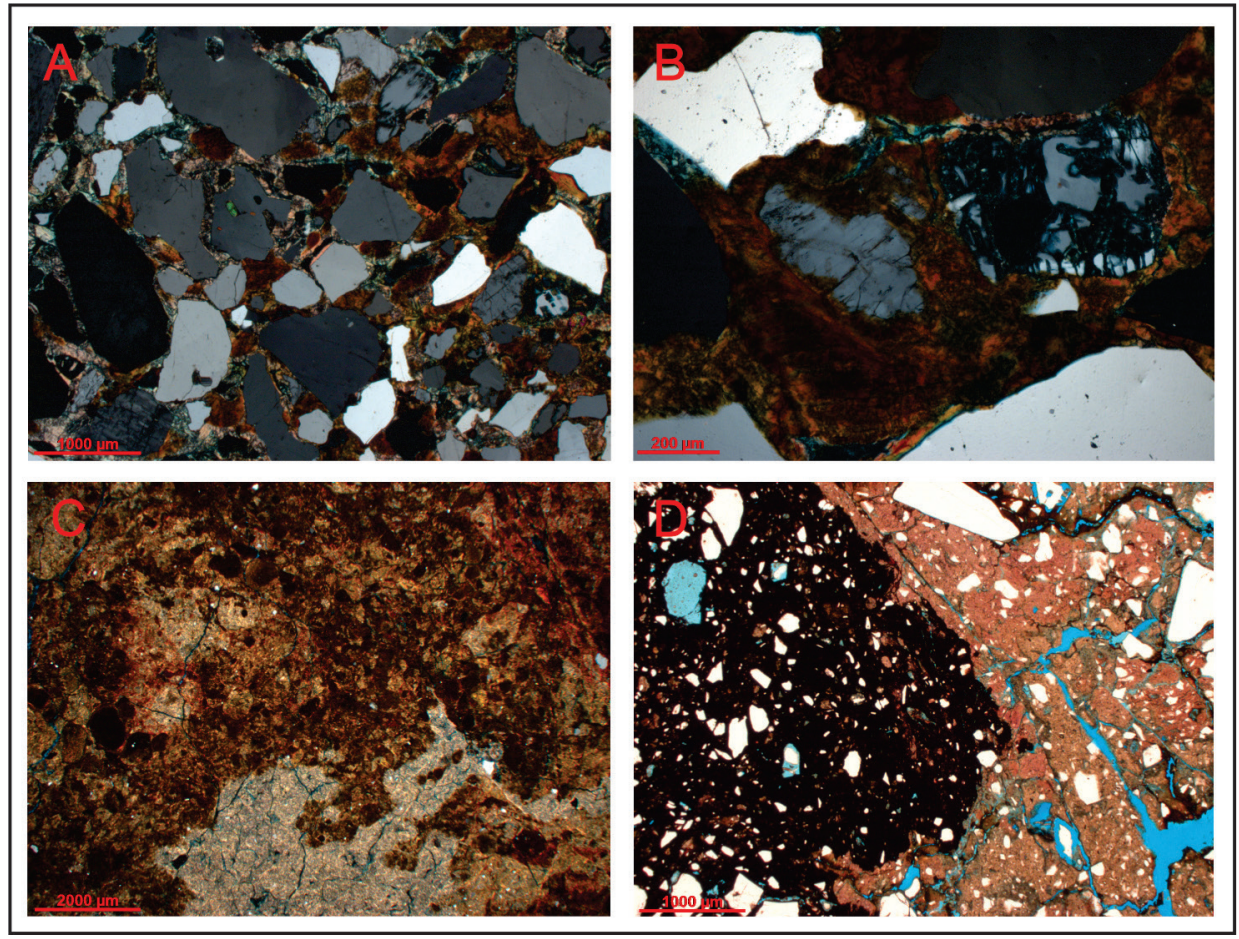

Figura 7. Aspectos petrográficos da porção inferior da SF-F1. A) Notar o baixo grau de seleção, o aspecto maciço e a composição essencialmente quartzosa (138,50 m/polarizadores cruzados); B) Notar argila infiltrada como cutículas cobrindo constituintes primários substituída por óxido/hidróxido de ferro (138,50 m/polarizadores cruzados); C) Notar matriz detrítica indiferenciada substituída por óxido/hidróxido de ferro (131,30 m/polarizadores cruzados); D) Notar óxido/hidróxido de ferro substituindo matriz e constituintes primários (136,10 m/polarizadores cruzados).

Figure 7. Petrographic features of the SF-F1 lower portion. A) Note the low degree of selection, the massive appearance and the essentially quartzous composition (138,50 m/cross polarizers); B) Note the infiltrated clay as cuticles covering primary constituents replaced by iron oxide/hydroxide (138.50 m/cross polarizers); C) Note the undifferentiated detrital matrix replaced by iron oxide/hydroxide (131.30 m/cross polarizers); D) Note iron oxide/hydroxide replacing matrix and primary constituents $(136.10 \mathrm{~m} /$ cross polarizers).

preferência por águas costeiras, alguns indivíduos podem ser transportados para estes locais em eventos de maior energia e ficarem preservados.

A ocorrência de ciclos de engrossamento granulométrico, com ritmitos adjacentes ou sotopostos e em estreita relação com sedimentos lamosos, como observado entre 71,85-35,70 m de profundidade (Fig. 2), são interpretados como depósitos progradacionais ou agradacionais de barras de desembocadura (mouth bar) associadas a fluxos desconfinados (fluxos hiperpicnais), que, neste contexto, marcam a estabilização do nível de base (nível do mar; c.f. Girard et al., 2012). Sotopostos aos ritmitos da SF-Dc ocorrem arenitos grossos com alterações pós-deposicionais, associados a depósitos de fluxos confinados em canais fluviais distributários, sugerindo condições cada vez mais proximais.

Com base nesses aspectos, a SF-Dc é interpretada como um sistema de delta de cabeceira de estuário (bay-head delta), componente morfológico proximal de estuários dominados por ondas, onde predominam depósitos terminais de canais fluviais, ricos em micas e fragmentos carbonosos e com pouca influência marinha, conforme proposto por Dalrymple et al. (1992). A sucessão marca três fases evolutivas distintas, a primeira, transgressiva, com a formação de um estuário; a segunda, um período de estabilização do nível do mar, que permitiu, sob condições de regressão normal, a progradação de um sistema deltaico; e, a terceira, um evento de regressão forçada (queda do nível de base) responsável pela exposição dos depósitos de canais distributários presentes do topo da sucessão (Fig. 2).

\subsubsection{Sucessão de fácies M (SF-M)}

A SF-M, restrita ao intervalo entre $33,40 \mathrm{~m}$ e 30,00 m (Fig. 2), é caracterizada por 
A

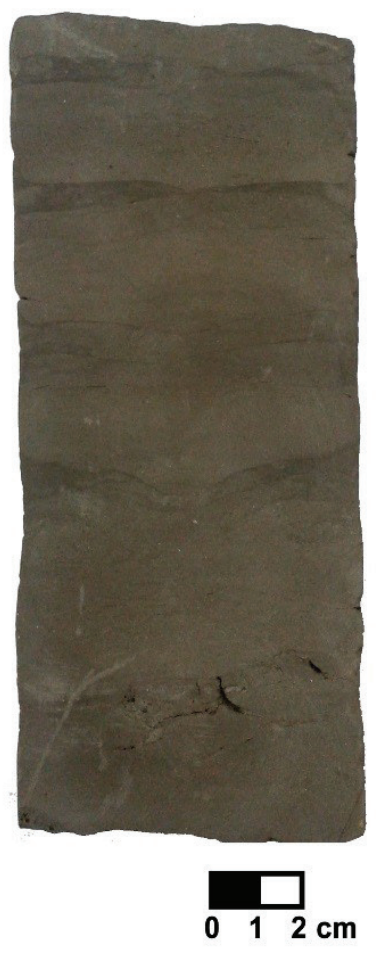

B

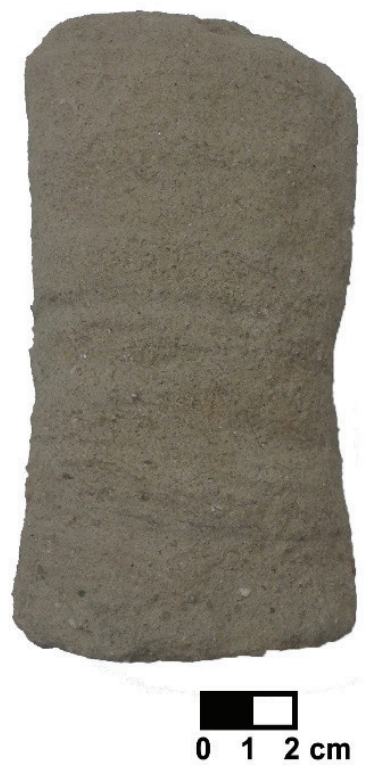

C

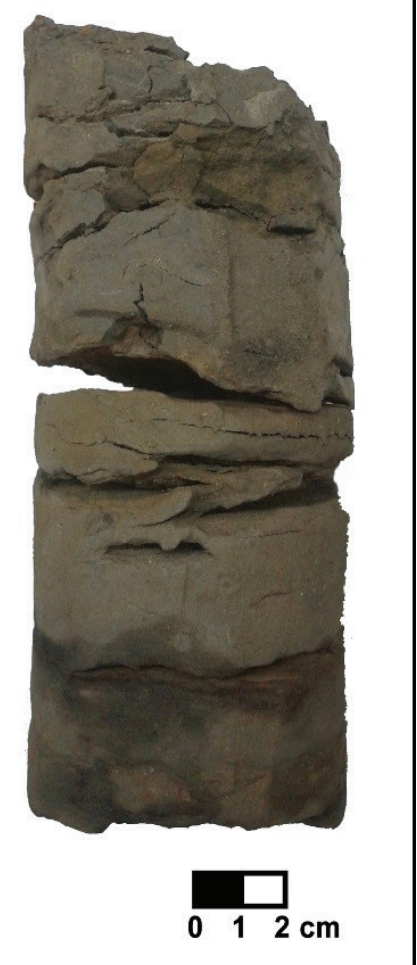

Figura 8. Fácies típicas da SF-Dc interpretada como um sistema de delta de cabeceira de estuário. A) Fácies LI (notar finas laminações marcadas por níveis mais escuros, onde há maior abundância de matéria orgânica); B) Fácies Ae (notar sutil orientação, marcada pelo acúmulo de matéria orgânica, caracterizando a estratificação); C) Fácies IF (notar rocha com acamamento heterolítico lenticular rica em matéria orgânica, em que as porções arenosas apresentam-se mais oxidadas).

Figure 8. Facies typical of the SF-Dc interpreted as a bay-head delta sistem. A) Facies LI (note thin laminations marked by darker levels with greater abundance of organic matter); B) Facies Ae (note subtle orientation marked by accumulation of organic matter, characterizing the stratification); C) Facies IF (note linsen bedding rich in organic matter, that sandy portions are more oxidized).

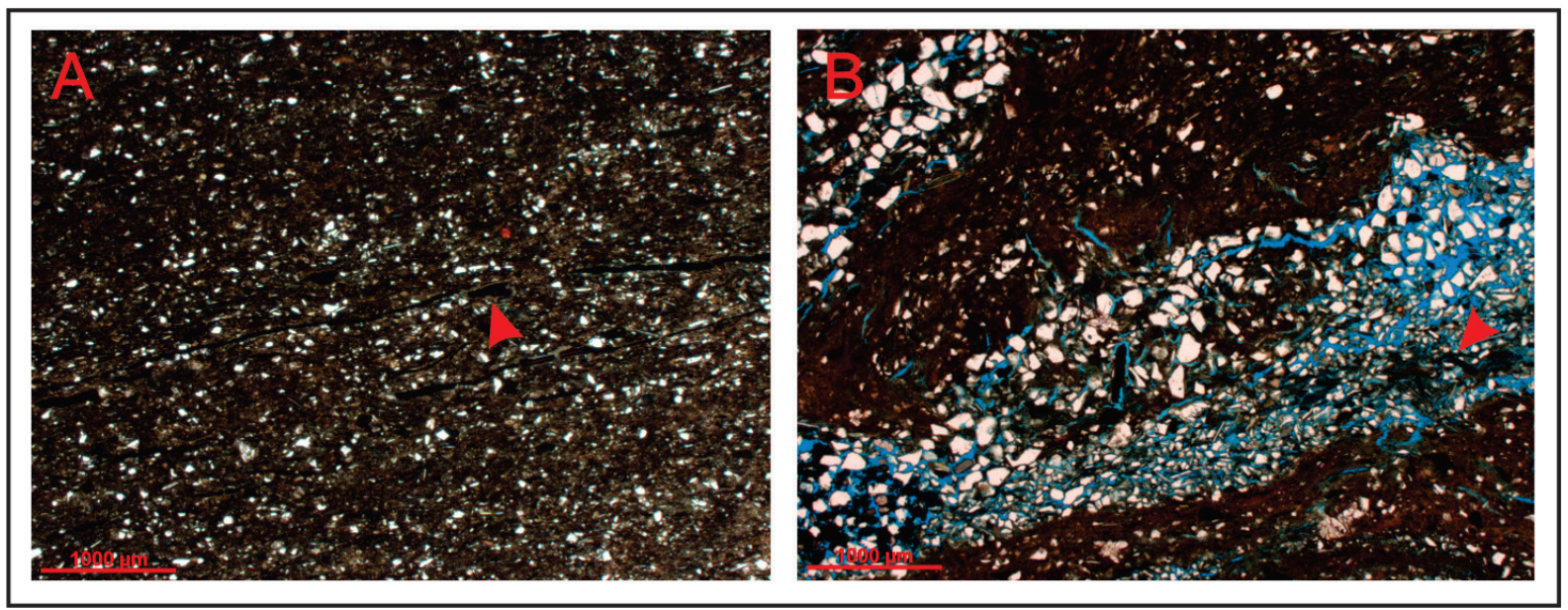

Figura 9. Aspectos petrográficos das fácies LI e IF exclusivas da SF-Dc. A) Notar laminação irregular dada pela orientação das micas e detritos vegetais (seta vermelha; $76,20 \mathrm{~m} /$ polarizadores paralelos); B) Notar níveis ricos em matriz detrítica e níveis ricos em quartzo e fragmento carbonoso (seta vermelha; 39,85 m/polarizadores paralelos).

Figure 9. Petrographic features of $\mathrm{LI}$ and IF facies exclusive to SF-Dc. A) Note irregular lamination given by micas and vegetable debris (red arrow) orientation $(76.20 \mathrm{~m} /$ parallel polarizers); B) Note levels rich in detrital matrix and levels rich in quartz and carbonaceous fragment (red arrow; $39.85 \mathrm{~m} /$ parallel polarizers). 
lamito híbrido oxidado (fácies Lh - Fig. 10A; Quadro 1) rico em bioclastos diversos (foraminíferos, bivalves, equinoides e moluscos, dentre outros) frequentemente inteiros e matriz margosa composta por nanofósseis calcários (ascídias e cocolitoforídeos), além de intraclastos carbonáticos indiferenciados (Fig. 11). A litologia e a nanofauna preservada apontam para uma sedimentação marinha de baixa energia, em um ambiente protegido da ação direta de ondas.

A base da sucessão marca uma superfície transgressiva (Fig. 2), responsável pelo rápido afogamento de ambientes costeiros, enquanto o aumento na proporção de sedimentos carbonáticos, podendo chegar aos 85\% no topo da sucessão, sugere um incremento da lâmina d'água e instalação de um ambiente marinho franco, associado ao máximo transgressivo (superfície de inundação máxima; Fig. 2).

Como os depósitos da SF-M encontramse oxidados, sendo comum observar óxido/ hidróxido de ferro substituindo a matriz carbonática (Fig. 11), sugere-se que a mesma marque também um evento de regressão forçada (Fig. 2). A queda relativa do nível do mar (queda do nível de base) promove a exposição subaérea dos depósitos marinhos e faz com que o sistema fluvial, anteriormente afogado, ganhe energia, o que favorece sua reinstalação e a retomada da sedimentação continental.

\subsubsection{Sucessão de fácies F2 (SF-F2)}

A SF-F2 ocorre entre $30,00 \mathrm{~m}$ e 13,40 m de profundidade (Fig. 2), sendo caracterizada, na base, por sedimentos finos da fácies Lm (Quadro 1), sucedida por camadas centimétricas de arenitos normalmente maciços (fácies Am Quadro 1), por vezes estratificados (fácies Ae Quadro 1), grossos a finos, subangulosos, mal selecionados, ricos em grânulos e com feições pedogenéticas.

A regressão forçada, responsável pela interrupção da sedimentação e pela exposição subaérea dos depósitos da SF-M, condicionou a instalação de um sistema fluvial. O padrão de empilhamento sedimentar indica que a instalação de tal sistema ocorreu em uma região ampla e plana, onde, sob altas taxas de criação de espaço de acumulação, formam-se canais isolados a amalgamados, em que o processo de avulsão é mais frequente do que o de migração lateral, permitindo a preservação dos finos da planície de inundação. Admite-se que para o topo da sucessão ocorra um aumento da migração lateral, promovida por uma diminuição na taxa de criação de espaço de acumulação, reduzindo o potencial de preservação da planície de inundação.

Aspectos texturais e composicionais indicam deposição e soterramento rápido, próximoàárea fonte, com pouco retrabalhamento. Admite-se que a SF-F2 esteja associada a deposição em um sistema fluvial meandrante ou wandering (modelo fluvial intermediário entre os padrões meandrante e anastomosado, q.v. Miall, 1996), que ocorrem com mais frequência em regiões de baixa declividade. A presença de feições pedogenéticas sugere longos períodos de exposição subaérea causados pela interrupção da sedimentação.

\subsubsection{Sucessão de fácies $L g(S F-L g)$}

A SF-Lg está compreendida entre 13,40 m e 10,40 m de profundidade (Fig. 2), sendo caracterizada por areias médias ricas em conchas de gastrópodes do gênero Heleobia australis e fragmentos de conchas de bivalves e com elevado conteúdo de matéria orgânica (Fácies Ab - Fig. 10B; Quadro 1). A SF-Lg marca um evento transgressivo responsável por afogar o sistema fluvial caracterizado na SF-F2 (Fig. 2) e instalar um ambiente sob influência marinha, desta vez de mais alta energia, com contribuição de fluxos hiperpicnais e, provavelmente, correntes de maré, responsáveis pelo elevado input de siliciclásticos e pela mistura entre os constituintes siliciclásticos e carbonáticos.

Os gastrópodes presentes nos depósitos da SF-Lg apontam para sedimentação em ambientes anóxicos, de regiões mixohalinas, sendo as maiores densidades populacionais encontradas em ecossistemas estuarinos e lagunas costeiras devido a chegada constante de matéria orgânica através do sistema fluvial alimentador (Fiori \& Carcedo, 2011). 


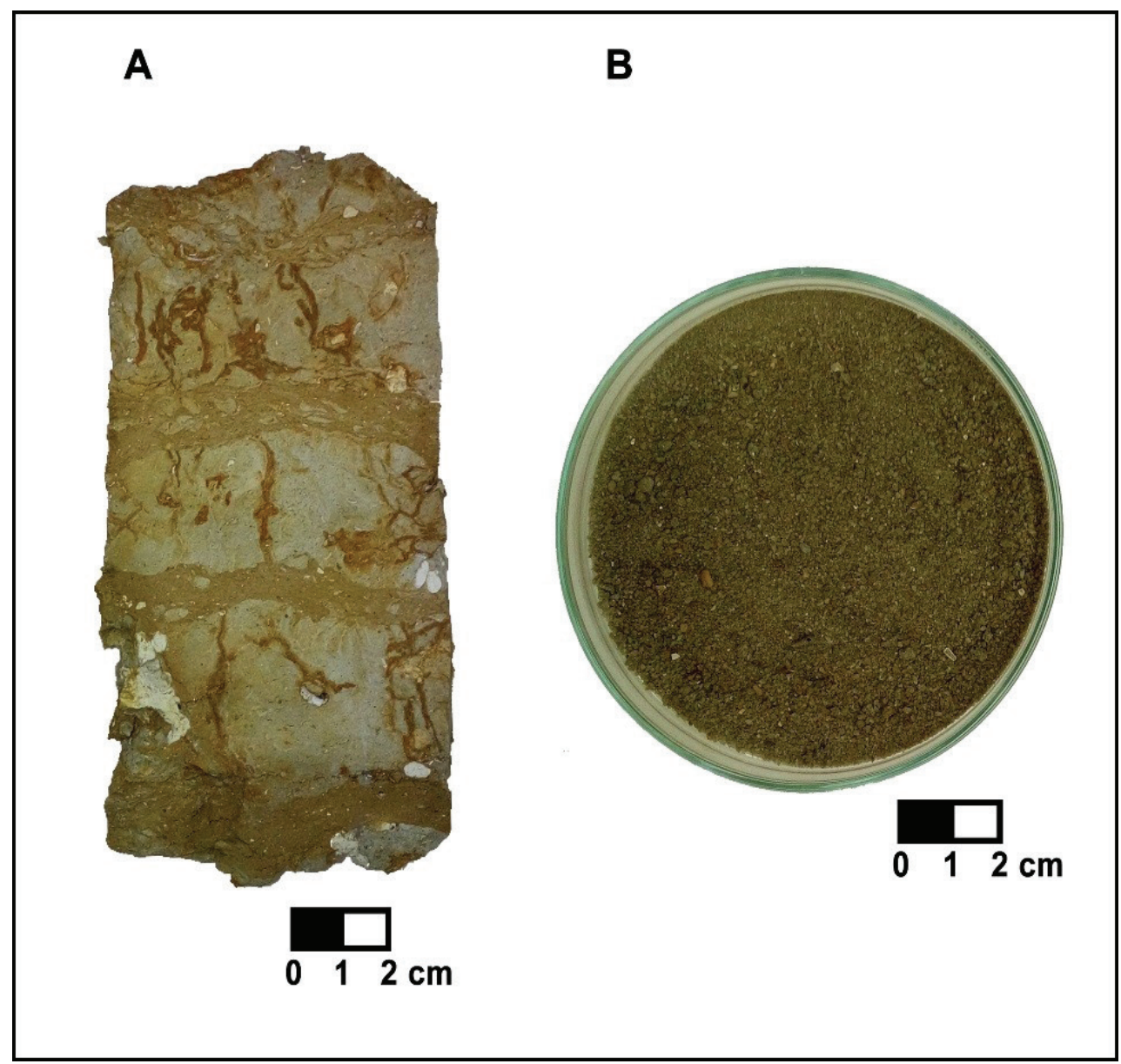

Figura 10. Fácies híbridas típicas das sucessões SF-M (marinho) e SF-Lg (lagunar). A) Fácies Lh (notar a presença de intraclastos carbonáticos indiferenciados e bioclastos imersos em uma matriz fina de composição essencialmente carbonática; a coloração amarelada indica modificação pós-deposicional); B) Fácies Ab, areia rica em bioclastos fragmentados e de coloração escura devido a elevada proporção de matéria orgânica e detritos vegetais.

Figure 10. Hybrid facies typical of the succesions SF-M (marine) and SF-Lg (lagoon). A) Facies Lh (note the undifferentiated carbonate intraclasts and bioclasts immersed in a fine carbonate matrix; the yellowish color indicates post-depositional changes); B) Facies Ab, sand rich in fragmented bioclasts, color dark due to high proportion of organic matter and vegetable debris.

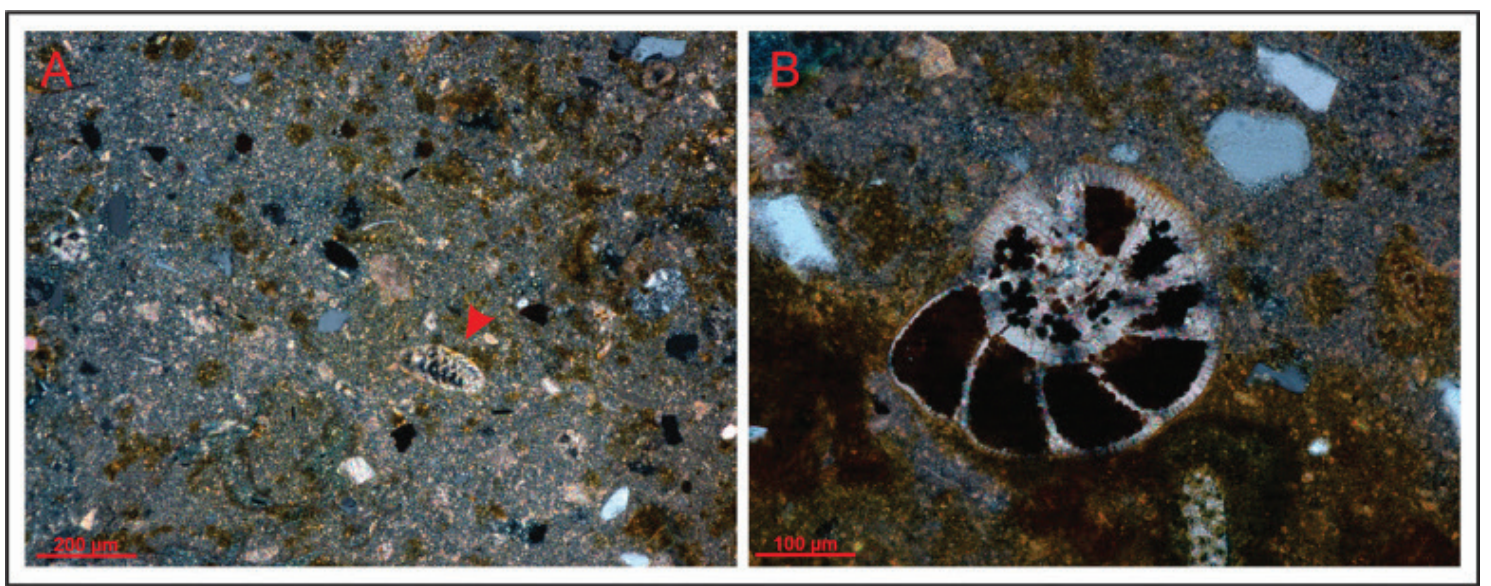

Figura 11. Aspectos petrográficos da fácies híbrida Lh exclusiva da SF-M. A) Visão geral onde se observa abundante matriz carbonática indiferenciada com cocólitos e raras ascídias, manchas acastanhadas típicas de processos de alteração pós-deposicionais e foraminífero bentônico (seta vermelha; 30,25 m/polarizadores cruzados); B) Em detalhe, pirita preenchendo porosidade intrapartícula em foraminífero bentônico imerso em matriz carbonática indiferenciada (30,25 m/polarizadores cruzados).

Figure 11. Petrographic features of the Lh hybrid facies exclusive to SF-M. A) An overview of abundant undifferentiated carbonate matrix with coccoliths and rare ascidians, brownish spots typical of post-depositional alteration processes and benthic foraminifera (red arrow; $30.25 \mathrm{~m} /$ cross polarizers); B) In detail, pyrite filling in intraparticle porosity in benthic foraminifera immersed in undifferentiated carbonate matrix $(30.25 \mathrm{~m} /$ cross polarizers). 


\subsubsection{Sucessão de fácies F3 (SF-F3)}

A SF-F3 ocorre entre 10,40 $\mathrm{m}$ de profundidade e o topo do testemunho (Fig. 2) e é caracterizada por areias micáceas e/ou feldspáticas, grossas a finas, subangulosas, mal selecionadas (fácies Amf - Quadro 1), formando ciclos métricos de afinamento granulométrico para o topo (finning upward). No topo da sucessão ocorre lamito maciço (fácies Lm - Quadro 1) com modificações pedogenéticas.

O padrão de empilhamento sedimentar está associado a um sistema fluvial meandrante. Neste contexto, a fácies Amf representaria barras arenosas, enquanto os lamitos maciços pedogeneizados da fácies $\mathrm{Lm}$ evidenciam a decantação de finos na planície de inundação, associada, de acordo com o descrito por Miall (1996), a períodos de cheia. A SF-F3 está disposta sobre sedimentos lagunares, sem quaisquer evidências de regressão marinha, o que permite interpretá-la como um sistema fluvial recente que se instalou em mar alto e estável, sendo responsável pela colmatação da paleolaguna representada pela SF-Lg.

\subsection{Difração de raio-X (DRX) em argilominerais}

Para caracterização dos argilominerais foram analisadas amostras representativas das fácies Lh (30,50 m), LI (51,60 m e 77,00 m), $\operatorname{Am}(150,50 \mathrm{~m}), \operatorname{LAm}(170,90 \mathrm{~m})$ e Lm $(27,60 \mathrm{~m}$ e 132,00 m), englobando cinco (SF-LA, SF-F1, SF-Dc, SF-M e SF-F2) das sete sucessões de fácies definidas (Fig. 2).

As sucessões basais do testemunho, SF-LA (172,30-155,30 m) e SF-F1 (155,30-90,00 m), são caracterizadas pela presença de caulinita e esmectitas. A SF-Dc (90,00-33,40 m) apresenta, além da caulinita e das esmectitas, gibbsita, sepiolita, vermiculita e muscovita. Os argilominerais da amostra representativa da SF-M (33,40-30,00 m) diferem dos da sucessão anterior pela ausência de sepiolita e presença de calcita. Já a assembleia mineralógica da SF-F2 (30,00-13,40 m) é caracterizada essencialmente por caulinita.

\subsection{Carbono orgânico total (COT)}

As 25 amostras coletadas ao longo do testemunho para determinação do carbono orgânico total (\% COT) e enxofre (\% S) (Fig. 2), englobam seis (SF-LA, SF-F1, SF-Dc, SF-M, SF-F2 e SF-Lg) das sete sucessões de fácies definidas. As análises forneceram valores de COT variando entre 0,03 e 2,78\% e de S entre 0,01 e 1,17\%, já a razão COT/S, oscilou entre 0,74 e 31,22, indicando desde condições redutoras até altamente oxidantes (Fig. 12).

A maior parte das amostras apresentou razão COT/S superior a 3, sendo os intervalos correspondentes a SF-F1 (155,30-90,00 m), SF-M (33,40-30,00 m) e SF-F2 (30,00-13,40 m) os que apresentam condições francamente oxidantes (Fig. 12), como já sugerido pela coloração predominantemente amarelada dos depósitos e por indícios de atuação de processos pedogenéticos.

Dentre as amostras representativas da SF-LA (172,70-155,30 m), nota-se uma tendência de aumento dos valores de COT/S, passando de um potencial redutor (COT/S $=2,7$ ) na base $(170,40 \mathrm{~m})$, para um potencial oxidante (COT/S = $4,6)$ em direção ao topo (165,60 m; Fig. 12). Esse aspecto é reforçado pela presença de manchas acastanhadas, mais abundantes em direção ao topo da sucessão.

Os valores de COT superiores a 0,5\% estão compreendidos entre $82,00 \mathrm{~m} \mathrm{e}$ $36,80 \mathrm{~m}$, englobando a SF-Dc $(90,00-33,40 \mathrm{~m})$, caracterizada pela ampla ocorrência de lamitos laminados ricos em detritos vegetais (fácies LI). Sugere-se, a partir disto, que se trata de um ambiente de baixa energia e com grande potencial de preservação da matéria orgânica. No entanto, com exceção das duas amostras do topo (36,80 m e 40,05 m), os baixos valores de enxofre (\% S) fazem com que as razões COT/S atinjam valores elevados (Fig. 12).

Por fim, a amostra correspondente a sucessão SF-Lg (13,40-10,40 m) apresenta valor de $\mathrm{COT} / \mathrm{S}<3$. 


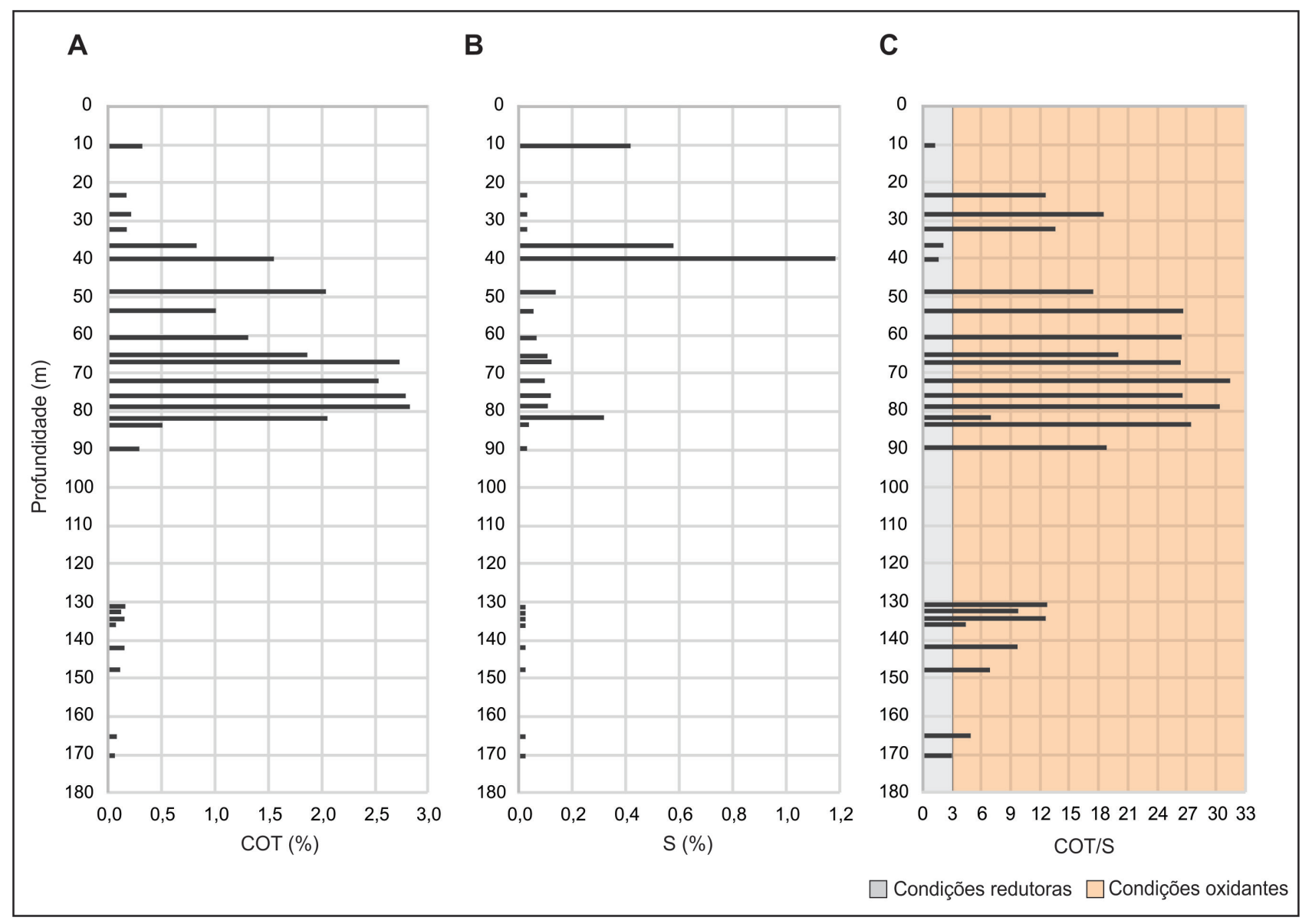

Figura 12. Análises geoquímicas realizadas em 25 amostras selecionadas ao longo do testemunho do poço 2-TO-1-RJ. A) Distribuição dos valores de carbono orgânico total (\% COT); B) Distribuição dos valores de enxofre (\% S); C) Distribuição dos valores obtidos a partir do cálculo da razão entre COT e S.

Figure 12. Geochemical analysis performed in 25 samples selected along the drillcore 2-TO-1-RJ. A) Distribution of total organic carbon values (\% TOC); B) Distribution of sulfur values (\% S); C) Distribution of the values obtained from the calculation of the ratio between TOC and $S$.

\subsection{Palinofácies}

Dentre as 26 amostras coletadas ao longo do testemunho do poço 2-TO-1-RJ e preparadas para o estudo de palinofácies (Fig. 2), apenas as 13 compreendidas entre $90,00 \mathrm{~m}$ e $33,40 \mathrm{~m}$ e a de 10,50 m apresentaram recuperação de matéria orgânica particulada (MOP). A análise permitiu a identificação dos três principais grupos de MOP e de alguns dos seus subgrupos: (i) Grupo Fitoclasto (69,8\%) - subgrupos nãoopacos bioestruturados e não-bioestruturados e cutículas; (ii) Grupo Amorfo (7,0\%) - subgrupos matéria orgânica amorfa e pseudoamorfa; e (iii) Grupo Palinomorfos (23,2\%) - subgrupos esporos, grãos de pólen, esporos de fungos e algas de água doce (e.g. Botryococcus e Pediastrum).
Os grupos e subgrupos de MOP identificados são estritamente de origem continental. Além da ausência de elementos marinhos, os fitoclastos opacos, indicadores de transporte prolongado e exposição subaérea, também não foram registrados. Com base nisto, a MOP foi agrupada em quatro associações de palinofácies (palinomorfos aquáticos, palinomorfos terrestres, fitoclastos não-opacos e matéria orgânica amorfa), que junto da ausência de MOP permitiram a identificação de cinco intervalos palinofaciológicos (I, II, III, IV e V) que apresentam boa correlação com as sucessões de fácies descritas para o testemunho (Fig. 13).

Os intervalos I (170,40-131,45 m), III (32,4023,50 m) e $V(\sim 1,40 \mathrm{~m})$ são diagnosticados pela não recuperação de MOP (Fig. 13). Os intervalos II (89,70-32,40 m) e IV ( 10,50 m) 
apresentam características bastante similares, sendo caracterizados pela elevada proporção de fitoclastos não-opacos (76-56\%) e presença de palinomorfos terrestres (48-13\%) e matéria orgânica amorfa (MOA) (12-1\%; Fig. 13).

As amostras de 83,40 m, 36,80 m e 10,50 m, pertencentes aos intervalos palinofaciológicos $\|$ e IV, apresentaram pequena proporção (máximo de $2 \%$ ) de algas de água doce (palinomorfos aquáticos; Fig. 13).

\subsection{Datação por radiocarbono $\left({ }^{14} \mathrm{C}\right)$}

$\mathrm{Na}$ tentativa de correlacionar o material de estudo com as variações quaternárias do nível do mar, duas amostras foram datadas por radiocarbono. As amostras pertencem as fácies híbridas $A b(10,50 \mathrm{~m}) \mathrm{eLh}(32,75 \mathrm{~m})$, características das SF-Lg e SF-M, respectivamente.

Para a amostra de 10,50 m a datação foi feita a partir de fragmentos vegetais (fitoclastos) e calibrada através de amostras de gastrópodes coletadas em Cabo Frio (Alves et al., 2015), obtendo-se assim idade convencional de $6.710 \pm 30$ anos AP e calibrada de 7.585-7.490 anos AP, enquanto para a amostra de $32,75 \mathrm{~m}$ foram datadas conchas e a idade obtida foi > 43.500 anos AP. Nesta última amostra não se alcançou idade precisa, sendo possível afırmar apenas que o material é mais antigo que 40.000 anos $A P$, tratando-se de uma sedimentação pleistocênica.

\section{Discussão dos resultados}

\subsection{Difração de raio-X (DRX) em argilominerais}

A associação entre caulinita, cuja formação é favorecida em regiões de clima quente e úmido, e esmectitas, que ocorrem preferencialmente em regiões de clima seco, caracteriza as sucessões SF-LA e SF-F1 e sugere que a sedimentação tenha ocorrido em um ambiente bem drenado, com boas condições de infiltração, onde, mesmo em regiões de clima mais seco, a formação da caulinita é favorecida. Um processo de infiltração eficaz intensifica a lixiviação dos cátions básicos $\left(\mathrm{Na}^{+}, \mathrm{K}^{+}, \mathrm{Ca}^{+2}\right)$ e as perdas parciais de silício, processos necessários à constituição da caulinita
(Azevedo \& Vidal-Torrado, 2009).

A presença de caulinita e gibbsita, argilominerais formados em ambiente onde o intemperismo químico é fortemente atuante, gerando grande lixiviação de cátions básicos e acúmulo de $\mathrm{Al}^{+3}$, associados com muscovita na SF-Dc sugerem origem detrítica com contribuição de alguma fonte fluvial próxima (Meunier, 2005). A ocorrência de vermiculita na referida sucessão está intimamente associada ao aporte de micas e ao curto tempo de intemperismo destes minerais, enquanto que a sepiolita pode se formar por precipitação em regiões de sedimentação essencialmente lamosa desde que o clima seja úmido, que prevaleça condições alcalinas e que Si, Mg, Al e Fe estejam disponíveis no meio (Akbulut \& Kadir, 2003).

A presença de calcita na amostra representativa da SF-M indica o aumento de circulação de águas marinhas e reforça o caráter híbrido (siliciclástico/carbonático) descrito para a fácies Lh, característica da sucessão. A presença quase que exclusiva de caulinita na SF-F2 marca deposição sob condições climáticas quentes e úmidas.

A partir das variações observadas nos argilominerais presentes ao longo do testemunho do poço 2-TO-1-RJ admite-se que a deposição das sucessões SF-LA e SF-F1 ocorreu em condições de clima mais seco, havendo uma importante mudança para condições climáticas quentes e úmidas a partir da SF-Dc.

\subsection{Palinofácies}

A não recuperação de MOP que caracteriza dos intervalos palinofaciológicos I, III e V (Fig. 13) pode, segundo Tucker (1991), ser associada a ambientes de alta energia, com sedimentação subaérea e/ou a depósitos de ambientes aquáticos que sofreram exposição subaérea, fazendo com que a matéria orgânica fosse completamente destruída por oxidação química e/ou microbiana.

Um alto suprimento de fitoclastos nãoopacos, como o observado nos intervalos palinofaciológicos II eIV (Fig. 13), indica deposição em estreita proximidade com um sistema fluvial alimentador e deposição em coluna d'água bem 


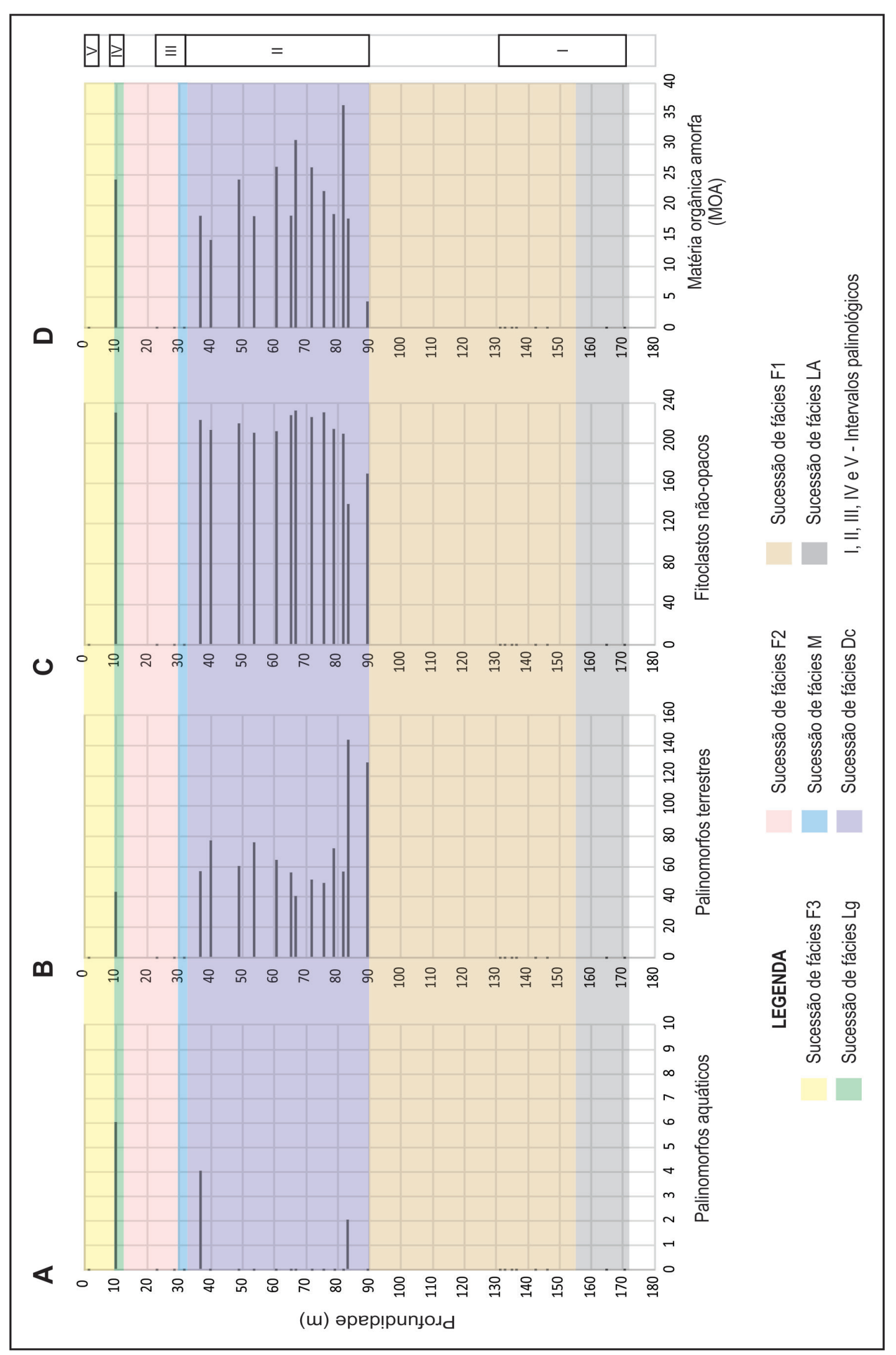

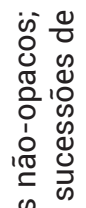

ว.

के

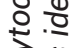

这

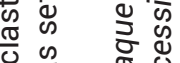

政

范

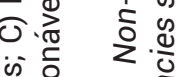

过

की $\frac{\pi}{0}$ के

힝 흔

\&) हो

$\stackrel{2}{\geq} \stackrel{1}{2}$

ब

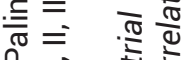

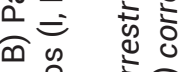

is .0

证高

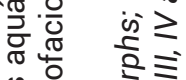

is 은

हो

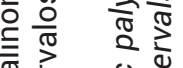

要

४ $\frac{1}{\circ} \frac{\pi}{0}$

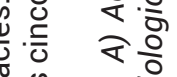

훙요

责造

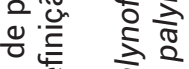

य)

然

西 क

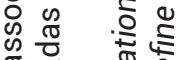

제

焉

व

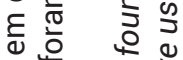

需娄

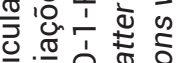

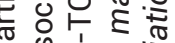

के 0

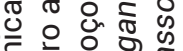

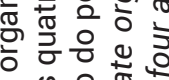

$\pi$ 里

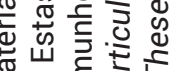

$\stackrel{0}{\varepsilon} \sigma$

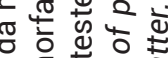

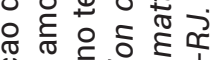

.

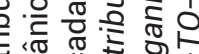
은 는 ๗் 
oxigenada, refletindo condições proximais de ambientes flúvio-lacustres ou, ainda, condições proximais de ambientes parálicos, como estuários e lagunas, onde o retrabalhamento e a degradação biológica são mais atuantes, não havendo transporte mecânico prolongado e tão pouco momentos de exposição subaérea (Tyson, 1995; Batten, 1996). Pontualmente, onde há aumento da proporção de palinomorfos terrestres e MOA, tem-se indicação de clima um pouco mais úmido e deposição em ambientes distais de baixa energia.

A ocorrência pontual de algas de água doce (palinomorfos aquáticos; Fig. 13), reitera que se trata de uma sedimentação sob lâmina d'água em região costeira, com um sistema fluvial alimentador em estreita proximidade. A ocorrência de algas do gênero Pediastrum sugere a existência de períodos de maior influência do sistema fluvial na sedimentação costeira, enquanto que a presença de Botryococcus, gênero que tolera grandes variações de salinidade, pode ser indicativo de períodos de maior circulação de águas marinhas. A maior ou menor intervenção fluvial neste tipo de ambiente varia, predominantemente, segundo o índice pluviométrico registrado na área da sua bacia hidrográfica.

\subsection{Evolução paleoambiental}

A análise do testemunho do poço 2-TO-1-RJ permitiu a caracterização de diferentes paleoambientes deposicionais (leque aluvial, fluvial, delta de cabeceira de estuário, marinho e lagunar) associados à evolução da porção central do CDRPS.

Os depósitos da SF-LA assemelham-se as associações de fácies descritas por Ramos et al. (2006) e Sanson et al. (2006) para a Formação Resende nas Bacias de Resende e Volta Redonda e, por Vilela (2015), para a Formação Emborê, na porção sul do CDRPS. Tais depósitos são relacionados a porções medianas a distais de leques aluviais, com retrabalhamento fluvial. A tendência de aumento nos valores de COT/S, passando de condições redutoras na base da SF-LA para condições oxidantes em seu topo, aponta para um aumento na contribuição de fluxos trativos, depositando e retrabalhando as porções distais deste sistema de leques aluviais.
A SF-LA transiciona para a

SF-F1 interpretada como depósitos fluviais entrelaçados de alta energia com contribuição de fluxos gravitacionais, ambos depositados sob condições climáticas um pouco mais secas, em um local bem drenado e com boas condições de infiltração. Os valores cada vez mais altos de COT/S e a não recuperação de matéria orgânica particulada indicam ambiente oxidante/altamente oxidante, de alta energia e com deposição subaérea.

Os depósitos areno-argilososconglomeráticos maciços, feldspáticos e de coloração cinza-esverdeada que compõem a SF-LA e os depósitos areno-argilosos oxidados e com estrutura incipiente da porção basal da SF-F1 (155,30-118,40 m) são similares ao descrito para o Membro São Tomé (Formação Emborê), cuja idade foi atribuída ao OligocenoPlioceno (Schaller, 1973; Gama Jr., 1977; Vilela et al., 2016).

Já a porção superior da SF-F1 (118,40-90,00 m) é caracterizada por depósitos arenosos inconsolidados depositados sobre arenitos intensamente oxidados, que marcam uma superfície de exposição subaérea gerada por regressão forçada. Tal evento é responsável por uma importante discordância na área de estudo (Fig. 2) e pode ser correlacionado ao terceiro estágio evolutivo de Martin et al. (1993), que corresponde a regressão subsequente ao máximo transgressivo de 210.000 anos AP (antepenúltima transgressão marinha). Desta forma, a porção superior da SF-F1, interpretada como um sistema fluvial entrelaçado de alta energia, representa o preenchimento inicial de um paleovale inciso, tratando-se, portanto, de uma sedimentação fluvial pleistocênica pós210.000 anos AP.

A existência de uma discordância subsequente ao máximo transgressivo de 210.000 anos AP, que representa o início da construção do CDRPS (Fig. 2) é também aventada por Plantz et al. (2018). Tais autores não relatam a existência de vale inciso, mas sugerem que o referido evento de regressão forçada tenha sido responsável tanto pela escavação de vales 
incisos quanto pela exposição e erosão subaérea das áreas altas adjacentes (interflúvios).

Por se tratar de uma região costeira, que evolui a partir das oscilações do nível do mar, a sedimentação essencialmente lamosa com ciclos de engrossamento granulométrico da SF-Dc é interpretada como um sistema de delta de cabeceira de estuário (bay-head delta), componente proximal de estuários, que está intimamente associado ao afogamento e preenchimento do vale inciso em um evento transgressivo-regressivo.

Apesar dos elevados valores de COT das amostras representativas da SF-Dc, as razões COT/S são > 3, fato que pode estar associado a ação de fluxos hiperpicnais, responsáveis pela deposição das barras de desembocadura e por oxigenar o meio, fazendo com que predomine condições disóxicas, também favoráveis a preservação da matéria orgânica. Dados de palinofácies e DRX sugerem forte contribuição de uma fonte fluvial próxima e indicam que a sedimentação ocorreu sob clima úmido, condição necessária ao desenvolvimento de fluxos hiperpicnais.

A ocorrência de fácies híbrida, constituída por uma mistura entre sedimentos siliciclásticos e carbonáticos, dentre os quais nano- e microfósseis, sugere a ocorrência de um novo evento transgressivo (Fig. 2). Com o sucessivo aumento da lâmina d'água ocorre a instalação de um ambiente marinho franco (SF-M), de idade pleistocênica (> 43.500 anos AP), sem quaisquer indícios da ação direta de ondas. O aumento na proporção de sedimentos carbonáticos, como o observado em direção ao topo da SF-M, é associado ao máximo transgressivo (Fig. 2).

Apesar dos indícios de sedimentação essencialmente marinha da SF-M, a ocorrência de argilominerais detríticos sugerem a presença de um sistema fluvial próximo, em que sedimentos continentais seriam carreados através de fluxos hiper- e homopicnais, mais frequentes e de maior magnitude durante eventos transgressivos que cobrem uma extensa plataforma continental (Mulder et al., 2003).

Bem como aventado por Plantz et al. (2018), que também descrevem rochas híbridas pleistocênicas (> 40.000 anos AP) em uma cota de aproximadamente $30,00 \mathrm{~m}$ de profundidade na porção central do CDRPS, este evento transgressivo pode ser correlacionado à penúltima transgressão marinha, cujo máximo transgressivo ocorreu em torno de 123.000 anos AP, quando o nível do mar atingiu $8 \pm 2 \mathrm{~m}$ acima do atual. Segundo Martin et al. (1993; 1997) a penúltima transgressão marinha cobriu toda a área do CDRPS, sendo responsável por retrabalhar as falésias esculpidas nos tabuleiros da Formação Barreiras e em parte do embasamento cristalino, a partir disto sugere-se que a ocorrência de rochas híbridas, recentemente relatada para o CDRPS, seja um importante marco estratigráfıco.

A não preservação de MOP e os elevados valores de COT/S da SF-M são atribuídos a uma fase regressiva, responsável por expor os depósitos marinhos à atmosfera oxidante e pela instalação de um novo sistema fluvial (SF-F2), ainda sob condições altamente oxidantes, em clima quente e úmido.

Admite-se que o topo da SF-F1 e as sucessões SF-Dc e SF-M estejam associadas ao evento transgressivo cujo máximo foi atingido em 123.000 anos AP (Pleistoceno Médio; Fig. 2). As superfícies estratigráficas interpretadas neste intervalo, bem como os depósitos da SF-F2 marcam eventos de menor ordem dentro de tendências globais.

A ocorrência de areias holocênicas da fácies Ab sobre os depósitos fluviais pedogeneizados da SF-F2, também atribuídos ao Pleistoceno Médio, indicam uma importante discordância na área de estudo (Fig. 2). Tal discordância pode ser relacionada ao evento global de glaciação, responsável pela queda do nível de base (regressão forçada), cujo máximo foi atingido em 18.000 anos AP, quando o nível do mar alcançou cerca de $110 \mathrm{~m}$ abaixo do atual.

Areias da fácies $A b$, característica da SF-Lg, sugerem uma sedimentação em ambiente parálico. Os valores de COT/S < 3 apontam para sedimentação em ambiente redutor e, segundo os critérios de Leventhal (1983), em paleoambiente com influência marinha, no entanto, a ocorrência de fitoclastos não-opacos em elevada proporção indica estreita proximidade com um sistema fluvial alimentador. 
Com base na idade e na interpretação paleoambiental, correlaciona-se a SF-Lg ao evento transgressivo holocênico (última transgressão marinha; Fig. 2), registro não recuperado no testemunho estudado por Plantz et al. (2018), mas relatado nos diversos modelos evolutivos propostos para o CDRPS (q.v. Martin et al., 1984; 1993; 1997; Silva 1987; Dominguez, 1990). Segundo Martin et al. (1997), uma laguna holocênica já existia há cerca de 7.000 anos AP e no momento máximo da transgressão, em 5.100 anos AP, quando o nível do mar teria alcançado $5 \pm 2 \mathrm{~m}$ acima do atual, as ilhas barreiras, responsáveis pelo isolamento da laguna, formavam uma grande reentrância ao norte do Cabo de são Tomé, onde encontravam-se as desembocaduras lagunares.

Sugere-se que, com a estabilização do nível do mar, o sistema fluvial tornou-se mais efetivo e iniciou a construção de um delta intralagunar, resultando na colmatação da laguna holocênica e instalação de uma extensa planície fluvial recente, representada pela SF-F3, de modo semelhante ao sugerido por Martin et al. (1997).

\section{Conclusões}

De modo geral, as análises realizadas para auxiliar na caracterização paleoambiental (DRX, COT e palinofácies) apresentaram correlação direta com as sucessões de fácies descritas para o testemunho do poço 2-TO-1-RJ, que revelam a importância das variações relativas do nível do mar na construção e evolução da porção central do (CDRPS).

Sugere-se que a evolução da porção central do CDRPS teve início com a regressão subsequente ao máximo da antepenúltima transgressão marinha (210.000 anos AP). A regressão teria sido responsável por erodir total ou parcialmente os depósitos pretéritos, gerando uma importante discordância marcada, no testemunho do poço 2-TO-1-RJ, por depósitos do Pleistoceno Médio (pós 210.000 anos AP) dispostos sobre depósitos oligocênicospliocênicos da Formação Emborê. A regressão foi responsável pela formação de vales incisos, através dos quais se iniciou a penúltima transgressão marinha (123.000 anos AP).
Tal transgressão alcançou toda a área correspondente ao CDRPS, sendo responsável por retrabalhar as linhas de falésias esculpidas nos depósitos da Formação Barreiras e em parte do embasamento cristalino, deixando como registro sedimentar depósitos estuarinos, que marcam a superfície transgressiva, e marinhos, caracterizados pela presença de bioclastos, nanoe microfósseis carbonáticos, que representam a superfície de inundação máxima.

Subsequente ao máximo transgressivo de 123.000 anos AP, ocorre uma sedimentação tipicamente continental, ainda associada ao Pleistoceno Médio, que é sucedida por depósitos parálicos com idade de 7.500 anos AP, marcando o início da sedimentação holocênica na área de estudo.

Os diversos modelos evolutivos propostos para o CDRPS contemplam a evolução holocênica com riqueza de detalhes. De modo geral, afirmam que entre 7.000 e 5.100 anos AP instalou-se um sistema lagunar barrado por um conjunto de ilhas barreiras, o qual foi parcialmente colmatado por um sistema fluvial, deixando a Lagoa Feia como resquício desta ampla paleolaguna, o que representa somente os primeiros 13,40 $\mathrm{m}$ do testemunho estudado (SF-Lg e SF-F3, respectivamente). Com uma abrangência muito maior, o presente trabalho é capaz de detalhar a sedimentação pleistocênica e as diversas fases de criação, preenchimento e destruição de espaço de acumulação que controlaram a evolução do CDRPS.

Agradecimentos. Os autores agradecem ao Projeto DELTA ("Arquitetura deposicional do complexo deltaico do rio Paraíba do Sul e seu papel na transferência sedimentar para águas profundas") financiado pela Chevron Brasil, com recursos de investimento em pesquisa e desenvolvimento para petróleo, gás natural e biocombustíveis - P\&D/ANP (conv. Fundação Coppetec IGEO - 15857) pela aquisição do material de estudo e financiamento da pesquisa; ao Claudio Limeira Mello pelas discussões que em muito contribuíram para a elaboração deste trabalho; e à Amanda Goulart Rodrigues pelo auxílio na descrição petrográfica. 


\section{Referências bibliográficas}

Akbulut, A. \& Kadir, S. 2003. The geology and origin of sepiolite, palygorskite and saponite in Neogene lacustrine sediments of the Serinhisar-Acipayam Basin, SW Turkey. Clays and Clay Minerals, 51: 279-292.

Alves, E., Macario, K., Souza, R., Pimenta, A., Douka, K., Oliveira, F., Chanca, I. \& Angulo, A. 2015. Radiocarbon reservoir corrections on the Brazilian coast from pre-bomb marine shells. Quaternary Geochronology, 29: 30-35.

Araújo, M.B. \& Beurlen, G. 1975. Projeto Rio Paraíba do Sul: Sedimentação Deltaica Holocênica. Rio de Janeiro, Petrobras/RPBaDIREX, no 1649, 37p. (Relatório Interno).

Azevedo, A.C. \& Vidal-Torrado, P. 2009. Esmectita, vermiculita, minerais com hidroxi- entre camadas e clorita. In: Melo, F.M. \& Aleoni, L.R.F. (Eds.). Química e mineralogia do solo - Parte I. Viçosa, SBCS, p. 382-426.

Bacoccoli, G. 1971. Os deltas marinhos holocênicos brasileiros - uma tentativa de classificação. Rio de Janeiro, Petrobras/ DIVEX/DEXPRO, no 14, p. 5-38. (Relatório Interno).

Batten, D.J. 1996. Palynofacies and paleoenvironmental interpretation. In: Jansonius, J. \& Mc Gregor D.C. (Eds.). Palynology: principles and applications, v.3. Texas, American Association of Stratigraphic Palynologists, p. 1011-1064.

Bernner, R.A. 1995. Sedimentary organic matter preservation: an assessment and speculative synthesis - a comment. Marine Chemistry, 49: 121-122.

Borghi, L. 2000. Visão Geral da Análise de Fácies Sedimentares do Ponto de Vista da Arquitetura Deposicional. Boletim do Museu Nacional (Nova Série, Geologia), 53: 126.

Borrego, J., Lopez, M., Pedon, J.G. \& Morales, J.A. 1998. C/S ratios in estuarine sediments of the Odiel River-mouth, S.W. Spain. Journal of Coastal Research, 14(4): 1276-1286.

Boyd, R., Dalrymple, R.W. \& Zaitlin, B.A. 1992. Classification of coastal sedimentary environments. Sedimentary Geology, 80: 139150.

Boyd, R. 2010. Transgressive Wave-Dominated
Coasts. In: James, N.P. \& Dalrymple, R.W. (Eds.). Facies Models 4. St. John's, Newfoundland, Geological Association of Canada, p. 265-294. Brêda, T.C. 2012. Análise multiescalar da Formação Barreiras na área emersa da Bacia de Campos, entre Búzios e Campos dos Goytacazes (RJ). Rio de Janeiro, 117p. Dissertação de Mestrado, Programa de Pós-graduação em Geologia, Instituto de Geociências, Universidade Federal do Rio de Janeiro.

Campbell, A.S. 1954. Radiolaria. In: Moore, R.C. (Ed.). Treatise on Invertebrate Paleontology. Part D - Protista 3: Protozoa (chiefly Radiolaria and Tintinnina). Lawrence, Geological Society of America and University of Kansas Press, p. 11-163.

Dalrymple, R.W., Zaitlin, B.A. \& Boyd, R. 1992. Estuarine facies models: conceptual basis and stratigraphic implications. Journal of Sedimentary Petrology, 62: 1130-1146.

Davis Jr., R. A. \& Fitzgerald, D. M. 2004. Beaches and Coasts. Londres, Blackwell Publishing, 419p.

Dominguez, J.M.L. 1990. Delta dominado por ondas: críticas às ideias atuais com referência particular ao modelo de Coleman \& Wright. Revista Brasileira de Geociências, 20: 352361.

Fiori, S.M. \& Carcedo, M.C. 2011. Estado actual del conocimiento sobre Heleobia australis y perspectivas futuras. In. Cazzaniga, N.J. (Ed.). El género Heleobia (Caenogastropoda Cochiopidae) en América del Sur. Sociedad Malacológica de Chile (SMACH), Amici Molluscarum, p. 28-30.

Folk, R.L. 1954. The distinction between grain size and mineral composition in sedimentar rocks. Journal of Geology, 62: 344-359.

Folk, R.L. 1968. Petrology of sedimentary rocks. Texas, Hemphill Publishing Company, 182p.

Gama Jr., E.G. 1977. Sistemas Deposicionais e Modelos de Sedimentação das Formações Campos e Emborê, Bacia de Campos, Rio de Janeiro, Brasil. São Paulo, 104p. Tese de Doutorado, Programa de Pós-graduação em Geologia, Instituto de Geociências, Universidade de São Paulo.

Gatto, A.L.M. 2016. Bioestratigrafia e 
Paleoceanografia de uma sucessão estratigráfica quaternária com base em Nanofósseis Calcários (Complexo deltaico do rio Paraíba do Sul, Bacia de Campos - RJ). Rio de Janeiro, 93p. Dissertação de Mestrado, Programa de Pós-graduação em Geologia, Instituto de Geociências, Universidade Federal do Rio de Janeiro.

Girard, F., Ghienne, J.F. \& Rubino, J.L. 2012. Occurrence of hyperpycnal flows and hybrid event beds related to glacial outburst events in a late Ordovician proglacial delta (Murzuq Basin, SW Libya). Journal of Sedimentary Research, 82: 688-708.

Lamego, A.R. 1944. Geologia Litorânea do Petróleo. Rio de Janeiro, Departamento Nacional de Produção Mineral, 147p.

Lamego, A.R. 1955. Geologia das Quadrículas de Campos, São Tomé, Lagoa Feia e Xexé. Rio de Janeiro, Departamento Nacional de Produção Mineral, 154p.

Lana, C.C. 2011. Dinoflagelados como indicadores paleoambientais durante a sedimentação eocretácea da porção terrestre da Bacia de Campos. In: Carvalho, I. S., Srivastava, N. K., Strohschoen, O. \& Lana C. C. (Eds.). Paleontologia: cenários de vida, v. 3. Rio de Janeiro, Interciência, p. 211-219.

Leventhal, J.S. 1983. An interpretation of carbon and sulfur relationship in Black Sea sediments as indicators of environments of deposition. Geochimica et Cosmochimica Acta, 47: 133137.

Lopes, A.L.M. 2004. Análise da evolução sedimentar quaternária da plataforma continental sul da Bacia de Campos com base em estratigrafia sísmica e sonografia. Niterói, 66p. Dissertação de Mestrado, Programa de Pós-graduação em Geologia e Geofísica Marinha, Departamento de Geologia e Geofísica, Universidade Federal Fluminense.

Martin, L., Suguio, K., Flexor, J.M., Dominguez, J.M.L. \& Azevedo, A.E.G. 1984. Evolução da planície costeira do rio Paraíba do Sul (RJ) durante o Quaternário: influência das variações do nível do mar. In: CONGRESSO BRASILEIRO DE GEOLOGIA, 33, 1984, Rio de Janeiro. Anais... Rio de Janeiro, SBG, v. 1, p. 84-97.
Martin, L., Suguio, K. \& Flexor, J.M. 1993. As flutuações do nível do mar durante o quaternário superior e a evolução geológica de "Deltas" brasileiros. Boletim de GeociênciasUSP (Publicação Especial), 15: 1-186.

Martin, L., Suguio, K., Dominguez, J.M.L. \& Flexor, J.M. 1997. Geologia do Quaternário costeiro do litoral norte do Rio de Janeiro e do Espírito Santo. Belo Horizonte, Serviço Geológico Brasileiro, 104p.

Mendonça Filho, J.G., Menezes, T.R., Mendonça, J.O., Oliveira, A.D., Carvalho, M.A., Sant'anna, A.J. \& Souza, J.T. 2010. Palinofácies. In: Carvalho, I.S. (Ed.). Paleontologia. Rio de Janeiro, Interciência, p. 283-317.

Meunier, A. 2005. Clays in Sedimentary Environments. In: Meunier, A. (Ed.). Clays. Potiers, Springer, p. 295-327.

Miall, A.D. 1996. The Geology of Fluvial Deposits: sedimentary facies, basin analysis, and petroleum geology. New York, Springer, 582p.

Morais, R.M.O. 2001. Estudo Faciológico da Formação Barreiras na região entre Maricá e Barra de Itabapoana, Estado do Rio de Janeiro. Rio de Janeiro, 113p. Dissertação de Mestrado, Programa de Pós-graduação em Geologia, Instituo de Geociências, Universidade Federal do Rio de Janeiro.

Mulder, T., Syvitski, J.P.M, Migeon, S., Faugères, J.C. \& Savoye, B. 2003. Marine hyperpycnal flows: initiation, behavior and related deposits. A review. Marine and Petroleum Geology, 20: 861-882.

Oliveira, J.P.M. 2015. Caracterização sismoestrutural do embasamento do complexo deltaico do rio Paraíba do Sul. Rio de Janeiro, 125p. Dissertação de Mestrado, Programa de Pós-graduação em Geologia, Instituo de Geociências, Universidade Federal do Rio de Janeiro.

Plantz, J.B., Carelli, T.G., Borghi, L. \& Carvalho, M.A. 2018. Evolução paleoambiental em uma sucessão estratigráfica no Complexo Deltaico do Rio Paraíba do Sul (RJ). GeociênciasUNESP, 37(4): 775-791.

Ramos, R.R.C., Mello, C.L. \& Sanson, M.S.R. 2006. Revisão estratigráfica da Bacia de Resende, Rift Continental do Sudeste do Brasil, Estado do Rio de Janeiro. GeociênciasUNESP, 25: 59- 
69.

Rocha, T.B., Fernandez, G.B., Peixoto, M.N.O. \& Rodrigues, A. 2013. Arquitetura deposicional e datação absoluta das cristas de praia pleistocênicas no complexo deltaico do Paraíba do Sul (RJ). Brazilian Journal of Geology, 43(4): 711-724.

Sanson, M.S.R., Ramos, R.R.C. \& Mello, C.L. 2006. Bacias Sedimentares Brasileiras: Bacia de Volta Redonda. Phoenix, 88: 1-6.

Schaller, H. 1973. Estratigrafia da Bacia de Campos. In: CONGRESSO BRASILEIRO DE GEOLOGIA, 27, 1973, Aracaju. Anais... Aracaju, SBG, v. 3, p. 247-258.

Selley, R.C. 1968. Facies profiles and other new methods of graphic data presentation: application in a quantitative study of Lybian Tertiary shorelines deposits. Journal of Sedimentary Petrology, 38(2): 363-372.

Silva, C.G. 1987. Estudo da evolução geológica e geomorfológica da região da Lagoa Feia, RJ. Niterói, 160p. Dissertação de Mestrado, Programa de Pós-graduação em Geologia e Geofísica Marinha, Departamento de Geologia e Geofísica, Universidade Federal Fluminense.

Silva, L.C. \& Cunha, H.C.S. 2001. Geologia do Estado do Rio de Janeiro: Mapa Geológico do Estado do Rio de Janeiro, escala 1:400.000, e Texto Explicativo. Brasília, Serviço Geológico Brasileiro, 1 CD-ROM.

Suguio, K. \& Nogueira, A.C.R. 1999. Revisão crítica dos conhecimentos geológicos sobre a Formação (ou Grupo?) Barreiras do Neógeno e o seu possível significado como testemunho de alguns eventos geológicos mundiais. Geociências-UNESP, 18(2): 461479.

Tucker, M.E. 1991. Sedimentary Petrology: An Introduction to the Origin of Sedimentary Rocks. Oxford, Blackwell Publishing, 262p.

Tyson, R.V. 1995. Sedimentary Organic Matter: Organic Facies and Palynofacies. Dordrecht, Kluwer Academic, 615p.
Vilela, P.C. 2015. Aspectos faciológicos e estratigráficos das formações Emborê e Barreiras no testemunho do poço 2-JU-1RJ - Quissamã (RJ), área emersa da Bacia de Campos. Rio de Janeiro, 42p. Dissertação de Mestrado, Programa de Pós-graduação em Geologia, Instituo de Geociências, Universidade Federal do Rio de Janeiro.

Vilela, P.C., Mello, C.L., Carelli, T.G. \& Borghi, L. 2016. Caracterização litológica do testemunho do poço 2-JU-1-RJ, na porção emersa da Bacia de Campos. Geociências-UNESP, 35(3): 346-358.

Manuscrito 714 | Recebido em jun. de 2017 | Aceito em dez. de 2018 | Editor: César L. Schultz 